\title{
Rotor Speed Control of a Direct-Driven Permanent Magnet Synchronous Generator-Based Wind Turbine Using Phase-Lag Compensators to Optimize Wind Power Extraction
}

\author{
Ester Hamatwi, ${ }^{1}$ Innocent E. Davidson, ${ }^{2}$ and Michael N. Gitau ${ }^{3}$ \\ ${ }^{1}$ Department of Electrical, Electronic and Computer Engineering, University of KwaZulu-Natal, University Road, \\ Durban 4000, South Africa \\ ${ }^{2}$ Department of Electric Power Engineering, Durban University of Technology, Corner of Botanic Gardens and Steve Biko Roads, \\ Durban 4000, South Africa \\ ${ }^{3}$ Department of Electrical, Electronics and Computer Engineering, University of Pretoria, Lynnwood Road, \\ Pretoria 0002, South Africa
}

Correspondence should be addressed to Ester Hamatwi; esterhamatwi@gmail.com

Received 12 January 2017; Revised 30 March 2017; Accepted 20 April 2017; Published 28 May 2017

Academic Editor: Carlos-Andrés García

Copyright (C) 2017 Ester Hamatwi et al. This is an open access article distributed under the Creative Commons Attribution License, which permits unrestricted use, distribution, and reproduction in any medium, provided the original work is properly cited.

\begin{abstract}
Due to the intermittent nature of wind, the wind power output tends to be inconsistent, and hence maximum power point tracking (MPPT) is usually employed to optimize the power extracted from the wind resource at a wide range of wind speeds. This paper deals with the rotor speed control of a $2 \mathrm{MW}$ direct-driven permanent magnet synchronous generator (PMSG) to achieve MPPT. The proportional-integral (PI), proportional-derivative (PD), and proportional-integral-derivative (PID) controllers have widely been employed in MPPT studies owing to their simple structure and simple design procedure. However, there are a number of shortcomings associated with these controllers; the trial-and-error design procedure used to determine the P, I, and D gains presents a possibility for poorly tuned controller gains, which reduces the accuracy and the dynamic performance of the entire control system. Moreover, these controllers' linear nature, constricted operating range, and their sensitivity to changes in machine parameters make them ineffective when applied to nonlinear and uncertain systems. On the other hand, phase-lag compensators are associated with a design procedure that is well defined from fundamental principles as opposed to the aforementioned trialand-error design procedure. This makes the latter controller type more accurate, although it is not well developed yet, and hence it is the focus of this paper. The simulation results demonstrated the effectiveness of the proposed MPPT controller.
\end{abstract}

\section{Introduction}

The increasing energy demand across the globe has led to an enormous interest in the cost-competitive, environmental friendly, and reliable renewable energy (RE) technologies to complement the conventional methods of generating electricity $[1,2]$. Wind energy has recently been proven to be technologically mature and fast-growing among all other $\mathrm{RE}$ sources due to the growth in the size of commercial wind turbine (WT) designs and the increase in the installed capacity worldwide [2-12]. Modern variable speed wind energy conversion systems (WECSs) are based on doubly fed induction generators (DFIGs) and permanent magnet synchronous generators (PMSGs) [3]. Although the DFIGs are well developed and have previously been widely applied in WECS due to their ability to achieve variable speed control with the reduced cost of converter requirements, the use of slip rings and the protection issues in the event of grid faults are the major drawbacks [8]. As a result, the PMSGbased WECSs have gained more popularity and preference over DFIG-based WECSs owing to their advantages such as high energy density, simple control methodology, high reliability, low maintenance cost, and the self-excitation system $[1,13,14]$. Moreover, direct-driven multipole PMSGs have been adopted to exclude the gearbox, which improves the efficiency of the WT and cuts down the weight of the nacelle 


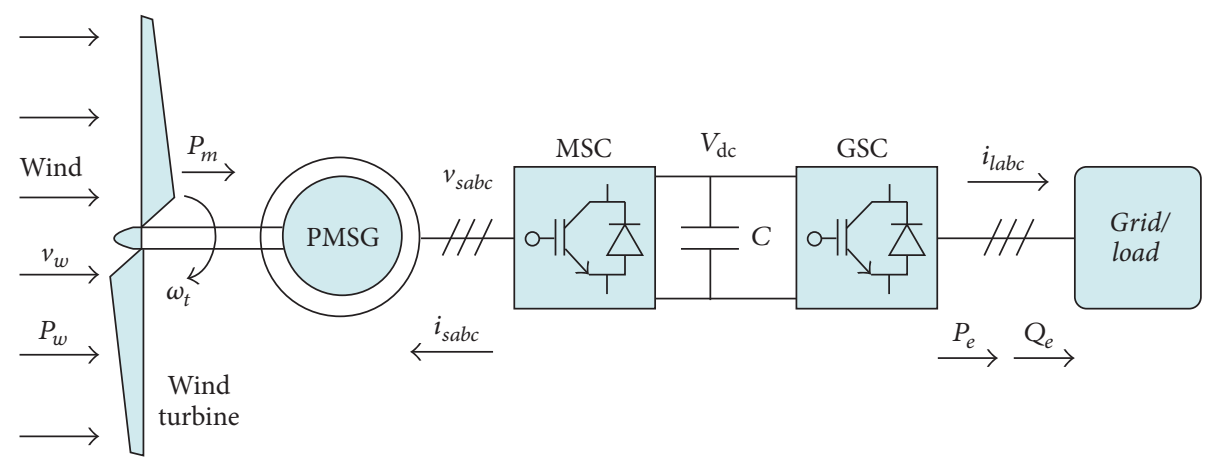

FIGURE 1: The direct-driven PMSG-based WECS [1].

and the operation and maintenance cost of the WT system $[3,13,15]$. The major challenge associated with WECS in general is the intermittent nature of the wind resource leading to an inconsistent wind power output. This inconsistency reduces the system stability and power quality of the electrical grid [6]. Therefore, power electronic converters are required to act as an interfacing medium between WECSs and the grid [16].

This will aid in achieving the grid compliance of the WECS in terms of the voltage level, frequency, active power, and reactive power [17-20]. A direct-driven PSMG-based WECS comprises a machine-side converter (MSC) and a grid-side converter (GSC) interconnected via a DC-link capacitor as shown in Figure 1.

The ability of a variable speed WT to extract optimal power at a wide range of wind speeds makes it possible to be operated in the MPPT mode $[1,12]$. Over the past years, various MPPT techniques have been developed, namely, optimal relationship-based (ORB) control, tip speed ratio (TSR) control, optimal torque control (OTC), and Perturb and Observe (P\&O)/Hill-Climb Search (HCS) control. Their operation, strengths, and weaknesses have been discussed in $[3,15,21-23]$. In this paper, the MPPT operation is achieved through the use of optimal relationship-based (ORB) control. The ORB control technique has gained interest because of its simplicity, quick response, and enhanced power smoothing capability and it is independent of the wind speed measurement [3]. The ORB control ensures optimal extraction of power from the wind resource by using a precalculated lookup table, and hence the knowledge of the WT's MPPT curve is a prerequisite $[3,24]$. On this basis, the amount of power extracted from the wind resource is controlled indirectly by varying the rotor speed $\omega_{r}$ with respect to the change in wind speed $v_{w}$. Therefore, optimal aerodynamic efficiency at a given wind speed can be achieved if the MPPT controller allows the generated power to properly track the predefined optimal power curve with variations in wind speed.

The direct (power angle) control and vector-oriented control (VOC) are the well-developed control techniques used to perform the independent control of active and reactive power in grid-connected WECS and they are discussed further in [25-27]. Freire et al. [25] compared the performance and effectiveness of the direct and VOC strategies. It was concluded that although the direct control technique is associated with a fast dynamic response and ease of implementation, the VOC technique has a better performance due to lower current distortions, higher grid power factor, and higher overall efficiency. Moreover, the VOC technique makes it possible to restrain the current stresses that the converter switches may experience during $\mathrm{AC}$ faults by limiting the input current to the rated maximum and minimum converter currents [28]. The VOC comprises a dual-loop structure: a slow outer control loop and a fast inner current control loop. The output signals from the outer control loops serve as reference currents for the inner current control loops.

Controllers are mainly incorporated into a system to improve the overall performance and stability of the system. This is done to meet certain design specifications such as percentage overshoot, rise time, settling time, phase margin, and a specified bandwidth [29-33]. The well-developed controllers used for the purpose of meeting the aforementioned design specifications can be classified into two categories:

(i) Proportional-derivative (PD), proportional-integral (PI), and proportional-integral-derivative (PID)

(ii) Phase-lag compensator, phase-lead compensator, and lag-lead compensator

Currently, PI, PD, and PID controllers are widely used in academia and in industrial control systems because they have a simple structure and simple design procedure and they are cost-effective [1, 14, 33-36]. However, the design procedure of PD, PI, and PID controllers involves determining the P, $\mathrm{I}$, and $\mathrm{D}$ gains which are usually tuned using a trial-anderror procedure $[1,36]$. Therefore, poorly tuned controller gains reduce the accuracy and the dynamic performance of the entire control system. Moreover, these controllers are linear, have a constricted operating range, and are prone to changes in machine parameters, and their design procedure does not take into consideration the initial performance of the uncompensated system $[2,35]$. Therefore, control systems comprising PI, PD, and PID controllers are ineffective when applied to nonlinear and uncertain systems [34].

On the other hand, phase-lead, phase-lag, and lag-lead compensators are associated with a design procedure that is well defined from fundamental principles as opposed to 
the trial-and-error design procedure. Moreover, the initial performance of the uncompensated system is taken into consideration prior to the controllers' modeling and design. The compensators are designed in the frequency domain to achieve the desired design specifications using bode plots and step-response curves. This makes the latter design procedure more accurate.

The literature review has shown that more focus has been put on employing PI controllers in several MPPT control studies for both DFIG-based and PMSG-based WECSs. However, although there have been a few studies on implementing phase-lag compensators in different control applications, particularly in DFIG-based WECS for low voltage ride through control by Wang et al. [37], there is a lack of research studies focusing on the implementation of these compensators in PMSG-based WECSs. Moreover, although nonlinear controllers are becoming more widely popular because they stabilize the nonlinear systems, in this context being WECSs, thereby providing a better performance and stability over a wide range of uncertain wind speed variations, their design procedure tends to be more complicated and they are still gaining their access into the industry and commercial products [38,39]. Contrariwise, according to Geng and Yang [38], linear controllers have a simpler structure and are easily understood and hence they are widely employed in the industry, of which PD, PI, and PID controllers have been frequently employed as opposed to the phase-lead, phaselag, and lead-lag compensators which are proposed in this research investigation. Therefore, the main aim of this paper is to close these gaps in literature by implementing phaselag compensators to control the machine-side converter of a PMSG-based WECS through the use of the dual-loopbased vector-oriented control technique. In this research investigation, the MPPT is achieved by employing the ORB technique to control the rotor speed of a $2 \mathrm{MW}$ direct-driven PMSG-based WECS during wind speeds lower than the WT's rated wind speed. The power electronic converters used in the proposed WECS are of a three-level Neutral Point Clamped (NPC) Voltage Source Converter (VSC) topology.

The research investigation discussed in this paper is motivated by a community-run wind power mini generation pilot project which is implemented in Lüderitz, a coastal town located in the southwestern Namibia, along the Namib Desert [40]. According to an experimental study by Davidson et al. [40], Lüderitz experiences abundant southwestern winds as high as $7.5 \mathrm{~m} / \mathrm{s}$ in summer and "Berg" winds ranging from $2.8 \mathrm{~m} / \mathrm{s}$ in winter. This makes it a suitable site for wind power plants. The demonstration site is made up of two $800 \mathrm{~W}, \mathrm{E} 230 \mathrm{i}$ PMSG-based wind turbines. The generation capacity of the mini power plant is in the range of $250-500 \mathrm{~W}$ [40]. This pilot project has brought about social and economic development and public awareness of RE technology in Namibia. Moreover, it is a starting point towards the reduction of the country's dependency on fossil fuels and importing of electricity from neighboring countries. However, this pilot project needs to be expanded to bring about more benefits. Therefore, this research investigation is the starting point of modularly expanding the wind-generation infrastructure in Namibia by thoroughly analyzing and designing the rotor speed controller of a 2 MW PMSG-based WECS to achieve MPPT. Subsequent work will then focus on hardware implementation and testing.

\section{Mathematical Modeling of a Wind Energy Conversion System}

2.1. Wind Turbine and Drive-Train Mathematical Modeling. The mechanical power extracted from the wind resource by the wind turbine is given by the following equation $[3,4]$ :

$$
P_{m}=\frac{1}{2} \rho A C_{p}(\lambda, \beta) v_{w}^{3},
$$

where $\rho$ is the air density which is equal to $1.225 \mathrm{~kg} / \mathrm{m}^{3}$ at sea level, $A$ is the area swept by the rotor blades $\left[\mathrm{m}^{2}\right]\left(A=\pi r^{2}\right.$, with $r$ being the radius of the rotor blade in $\mathrm{m}$ ), $v_{w}$ is the wind speed upstream of the rotor $[\mathrm{m} / \mathrm{s}]$, and $C_{p}$ is the aerodynamic power coefficient dependent on the blade-pitch-angle 9 [deg] and tip speed ratio $\lambda$ given by the following equation $[3,4]$ :

$$
\lambda=\frac{r \times \omega_{r}}{v_{w}},
$$

where $\omega_{r}$ is the rotor angular speed $[\mathrm{rad} / \mathrm{s}]$.

\subsection{Permanent Magnet Synchronous Generator Mathematical} Model. The dynamic modeling of a PMSG is normally carried out in the direct-quadrature $(d q)$ synchronous reference frame with $q$-axis $90^{\circ}$ ahead of $d$-axis with respect to the direction of rotation [41]. The detailed mathematical modeling and equations describing a PMSG have been discussed in more detail in Kundur [42]. The dynamic equations of the PMSG in the $d q$ synchronous reference frame are given as follows $[41,43]$ :

$$
\begin{aligned}
& V_{s d}=R_{s} i_{s d}+L_{s d} \frac{d i_{s d}}{d t}-\omega_{e} L_{s q} i_{s q}, \\
& V_{s q}=R_{s} i_{s q}+L_{s q} \frac{d i_{s q}}{d t}+\omega_{e}\left(L_{s d} i_{s d}+\psi_{f}\right),
\end{aligned}
$$

where $u_{s d}$ and $u_{s q}$ are the $d$-axis and $q$-axis stator voltages [V], respectively; $i_{s d}$ and $i_{s q}$ are the $d$-axis and $q$-axis stator currents [A], respectively; $L_{s d}$ and $L_{s q}$ are the $d$-axis and $q$ axis inductances $[\mathrm{H}]$, respectively; $R_{s}$ is the stator winding resistance $[\Omega] ; \psi_{f}$ is the permanent magnetic flux [Wb]; and $\omega_{e}$ is the electrical rotating speed $[\mathrm{rad} / \mathrm{s}]$ of the generator.

\section{Control System Modeling}

\subsection{Fundamentals of Control Systems}

3.1.1. Gain and Phase Margin. In the frequency domain, the gain and phase margins are the important indicators of system robustness, performance, and stability and hence they are widely used for controller designs. Phase and gain margins are determined by using Bode plots of the system's open-loop transfer functions. A gain margin is referred to as the amount of additional open-loop gain, expressed in decibels $(\mathrm{dB})$, 


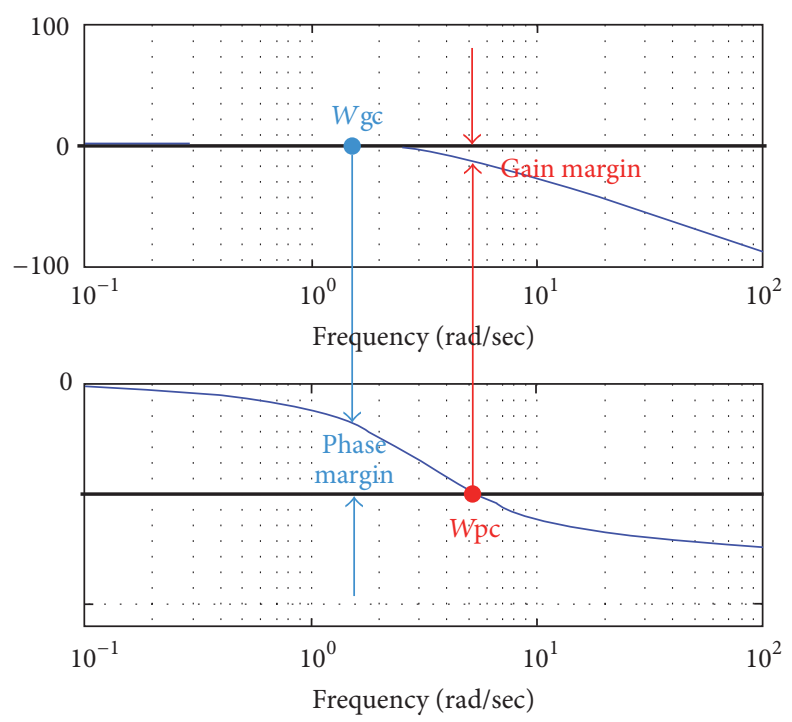

FIGURE 2: Graphical representation of the gain and phase margin and their corresponding crossover frequencies.

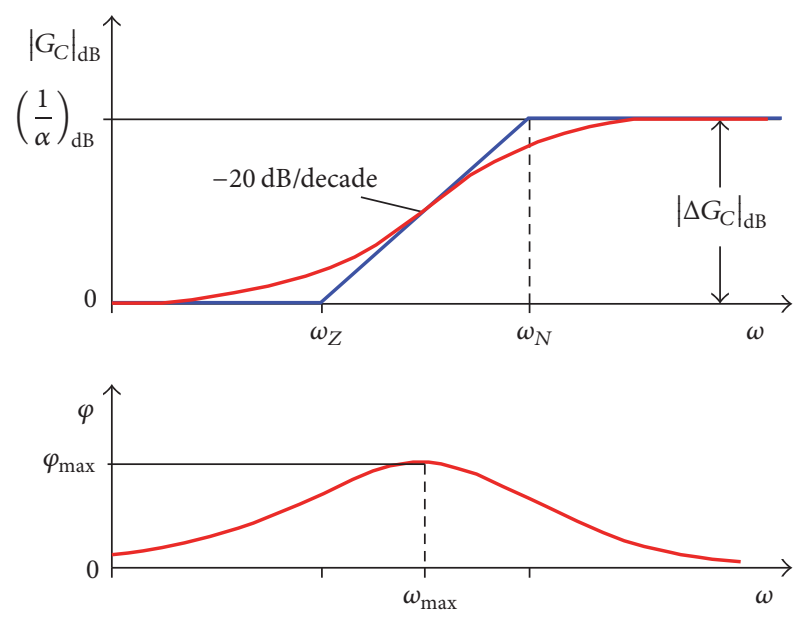

(a)
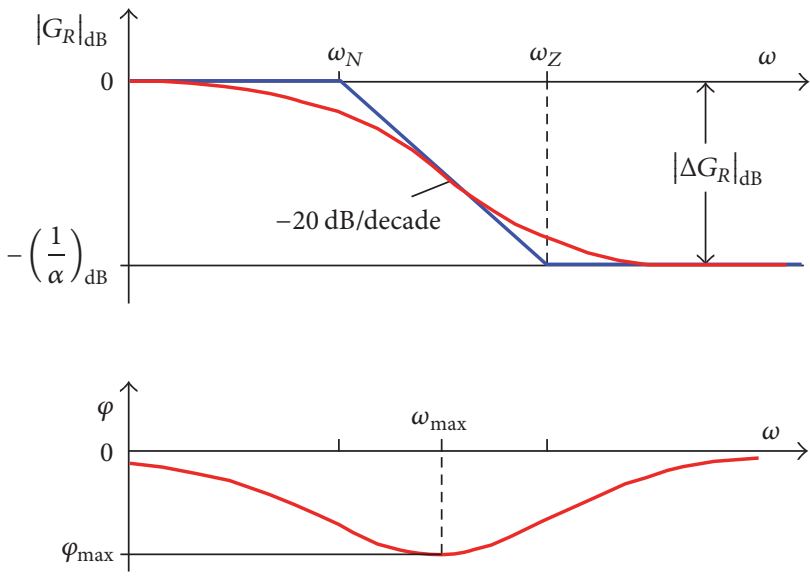

(b)

FIGURE 3: Magnitude and phase curves: (a) phase-lead compensator and (b) phase-lag compensator.

which is needed to make the closed-loop system unstable. The phase margin is referred to as the additional open-loop phase shift which is needed at unity gain to make the closed-loop system unstable $[44,45]$. Figure 2 shows the gain and phase margin and their corresponding crossover frequencies.

3.1.2. Phase-Lead and Phase-Lag Compensators. The phaselead compensator improves the performance of the openloop system by adding a phase boost to the phase curve to obtain the desired phase margin at the desired gain crossover frequency [29], whereas the phase-lag compensator improves the performance of the open-loop system by adding phase attenuation to the phase curve to obtain the desired phase margin at the desired gain crossover frequency [31]. Figures 3(a) and 3(b) show the bode plot indicating the magnitude and phase curves of typical phase-lead and phaselag compensators, respectively.
3.1.3. Lead-Lag Compensator. The lag-lead compensator combines the features and functions of the phase-lead and phase-lag compensators. Therefore, it is just a series connection of the two compensators.

3.1.4. Design Specifications. Controllers are mainly incorporated into a system to improve the overall performance and stability of the system. This is done to meet certain design specifications such as percentage overshoot, rise time, settling time, phase margin, and a specified bandwidth [2933]. Therefore, the stability of the proposed controllers is ensured by verifying that the controllers have enabled the desired design specifications to be achieved when they have been incorporated into the entire system. This is analyzed by comparing the measured values to the desired/reference values. These values must correspond to or have a small margin of error, and, in terms of plots, the measured values' 


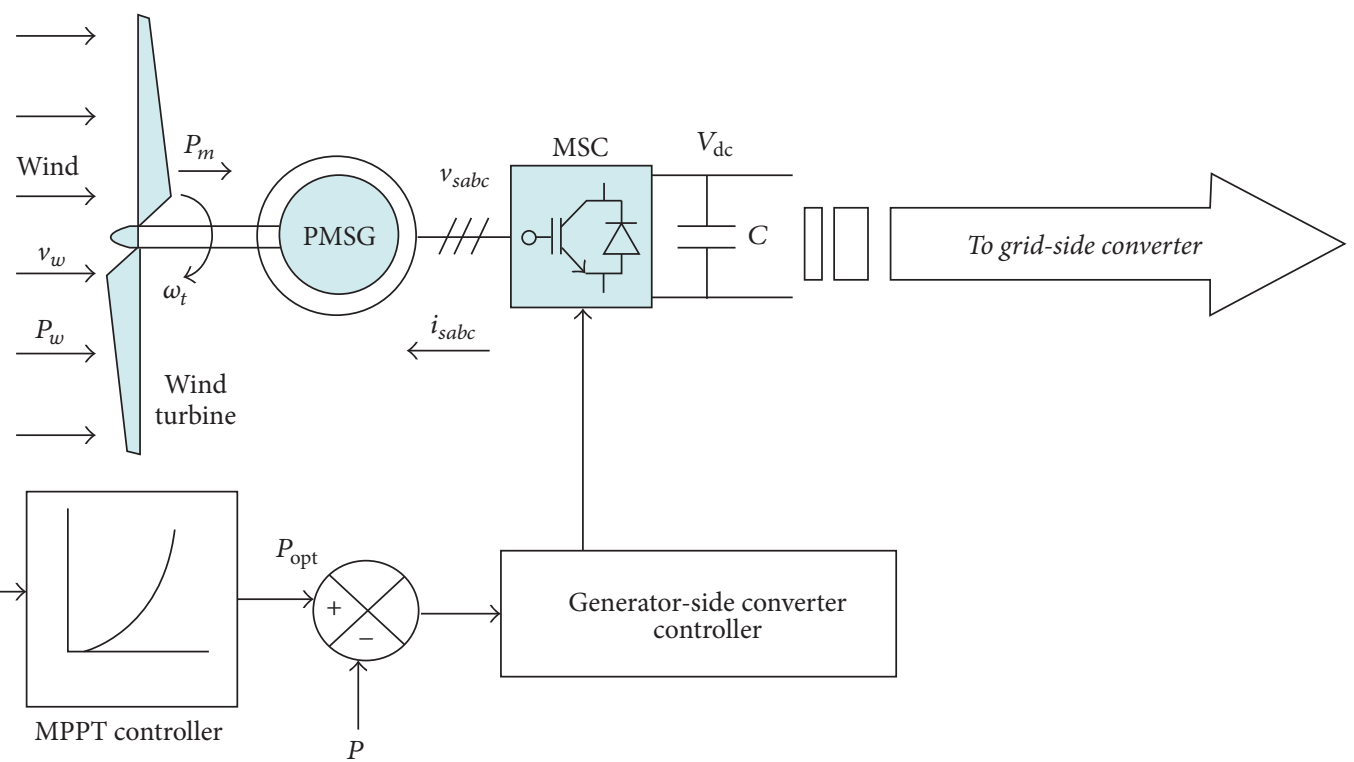

FIGURE 4: Schematic diagram of the PMSG-based WECSs.

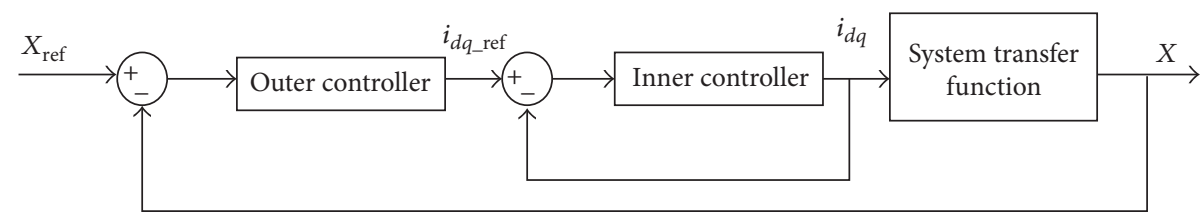

FIGURE 5: Block diagram of a typical converter controller.

curve(s) must closely track the reference values' curve(s). This analysis will be carried out and discussed throughout the paper.

The percentage overshoot refers to the amount by which the waveform overshoots the steady-state value at peak time. It is related to the damping ratio $\zeta$ by the following equation [45]:

$$
\mathrm{OS}=e^{-\pi \zeta / \sqrt{1-\zeta^{2}}}
$$

The phase margin is related to the damping ratio by the following equation [45]:

$$
\mathrm{PM}=\tan ^{-1}\left(\frac{2 \zeta}{\sqrt{\sqrt{1+4 \zeta^{2}}-2 \zeta^{2}}}\right) .
$$

The natural frequency of the system is related to the specified bandwidth and damping ratio by the following equation $[44,45]$ :

$$
\omega_{n}=\frac{\omega_{\mathrm{BW}}}{\sqrt{\left(1-2 \zeta^{2}\right)+\sqrt{\zeta^{4}-4 \zeta^{2}+2}}} .
$$

The settling time of the controller is related to the system's natural frequency and damping ratio by the following equation $[44,45]$ :

$$
T_{s}=\frac{4}{\omega_{n} \times \zeta}
$$

The rise time of the controller is related to the system's natural frequency and damping ratio by the following equation $[44,45]$ :

$$
T_{r}=\frac{1.76 \zeta^{3}-0.417 \zeta^{2}+1.039 \zeta+1}{\omega_{n}} .
$$

\subsection{Machine-Side Converter Controller}

3.2.1. Controller Objective. The maximum power point tracking (MPPT) is achieved by the machine-side converter (MSC) controller. This is done by adjusting the generator speed relative to the change in the wind speed. Figure 4 shows the schematic diagram of the proposed WECS with the MPPT controller and the generator-side converter controller.

Figure 5 shows a typical control block of a converter station employing a dual-loop structure: a fast inner current control loop and a slower outer control loop.

3.2.2. Derivation of the Transfer Functions: Inner Current Control Loop. Figures 6(a) and 6(b) show the initial and final inner current control loops for the generator-side converter, respectively.

A converter is usually considered as an ideal transformer with a time delay caused by the switching of the converter switches. The delay time is equal to the half of the switching 


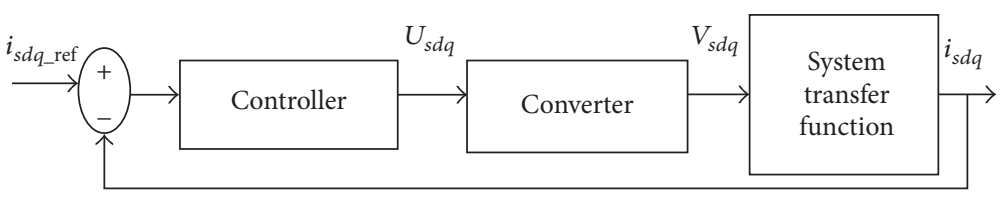

(a)

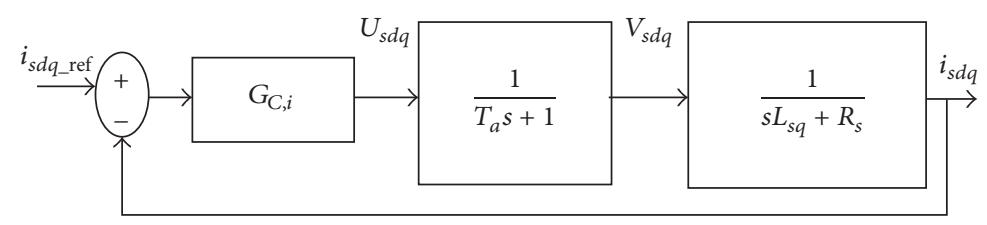

(b)

FIGURE 6: Inner current control loop for the generator-side converter: (a) initial control loop and (b) final control loop.

time. The transfer function of the converter block is therefore given by the following equation [46]:

$$
Y(s)=\frac{1}{T_{a} s+1}
$$

where $T_{a}=T_{\text {switch }} / 2=1 / 2 f_{\text {switch }}$ is the time delay in seconds.

The system's behavior is governed by the equations that represent the PMSG's stator voltages in $d q$ synchronous reference frame given in (3). The $d$-components and $q$ components of the stator voltage have a speed or frequency induced term $\omega_{s e} L_{s q} i_{s q}$ and a speed or frequency and a flux induced term $\omega_{s e}\left(L_{s d} i_{s d}+\psi f\right)$, respectively, which ensures the cross-coupling between the two axes. Decoupling $d$ axis and $q$-axis ensures a good control system performance [10]. Removing the cross-coupling terms gives (10) which represent the system's transfer function in Figure 6(a):

$$
\begin{aligned}
& V_{s d}=R_{s} i_{s d}+L_{s d} \frac{d i_{s d}}{d t} \\
& V_{s q}=R_{s} i_{s q}+L_{s q} \frac{d i_{s q}}{d t} .
\end{aligned}
$$

Taking the Laplace transformation of (10) gives (11) relating the output stator current to the stator voltage:

$$
\frac{i_{s d}(s)}{V_{s d}(s)}=\frac{i_{s q}(s)}{V_{s q}(s)}=\frac{1}{s L_{s d q}+R_{s}} .
$$

From Figure 6(b), the open-loop transfer function of the inner current control loop is given by the following equation:

$$
G_{i, \mathrm{ol}}(s)=\frac{G_{C, i}(s)}{(s T a+1)\left(s L_{s d q}+R_{s}\right)}
$$

3.2.3. Design Specifications of the Inner Current Controller. To prevent the ripple generated during the switching of the pulse width modulation (PWM) converter switches from affecting the controller's performance, it is recommended that the inner current controller's bandwidth should be as wide as possible and at least be less than or equal to one-fourth of PWM converter's switching frequency [2]. The choice of the PWM converter's switching frequency mainly depends on the switches' blocking voltage (collector-emitter voltage) and the current carrying capacity. According to $[47,48]$, the IGBTs are preferred over MOSFETs for blocking voltages above $250 \mathrm{~V}$ and they usually operate at low frequencies less than $20 \mathrm{kHz}$ for motor drive/control. In this study, the PWM converter is rated at $3 \mathrm{MVA}$, above the apparent power rating of the WT given in Table 2.

Considering the wind turbine's rated line-to-line voltage of $690 \mathrm{~V}$ as given in Table 2, the switching frequency is taken to be $10 \mathrm{kHz}$. Therefore, the bandwidth of the inner current control loop is taken to be $2.5 \mathrm{kHz}$, which is one-fourth of the PWM converter's switching frequency. The percentage overshoot of the inner current control loop is taken to be $25 \%$, since the inner loop is fast, and hence the system can recover from the overshoot faster. Therefore, the damping ratio and phase margin calculated using (4) and (5) are equal to 0.404 and $39.52^{\circ}$, respectively. Furthermore, the settling time and rise time of the inner current controller calculated using (7) and (8) are equal to $0.856 \mathrm{~ms}$ and $0.127 \mathrm{~ms}$, respectively.

(1) The Uncompensated Inner Current Control Loop. The bode plot used for the system's stability analysis is plotted using (12) by substituting in the delay time, the synchronous inductance, and stator winding resistance given in Table 2. The delay time calculated using (9) is equal to $50 \mu \mathrm{s}$. Therefore, the open-loop transfer function is given by the following equation:

$$
\begin{aligned}
& G_{I, \text { OL_uncompen }}(s) \\
& \quad=\frac{G_{C, i}(s)}{78 \times 10^{-9} s^{2}+1.573 \times 10^{-3} s+0.821 \times 10^{-3}} .
\end{aligned}
$$

Figure 7 shows the bode plot of the uncompensated openloop transfer function of the inner current controller; that is, $G_{C, i}(s)=1$.

It is observed that the phase margin and bandwidth of the uncompensated system are $88.2^{\circ}$ and $635 \mathrm{rad} / \mathrm{s}$, respectively. The bandwidth is too low as compared to the desired value of $1.57 \times 10^{4} \mathrm{rad} / \mathrm{s}(2500 \mathrm{~Hz})$ and hence the system response will be too slow. Furthermore, the phase margin is too high and much closer to $90^{\circ}$. 


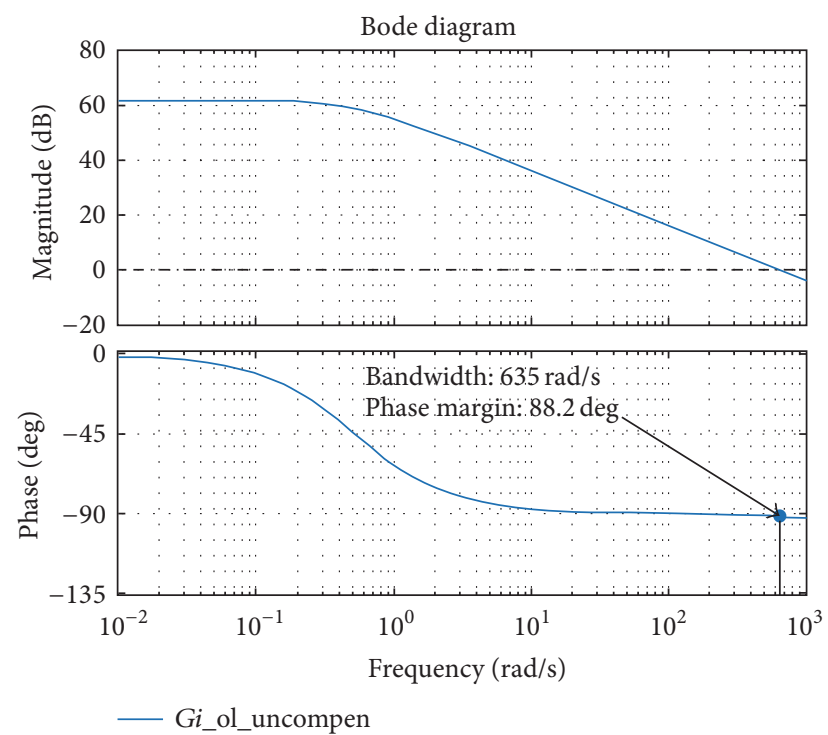

Figure 7: Bode plot of the uncompensated open-loop transfer function.

To obtain the desired bandwidth, the system's open-loop transfer function needs to be multiplied by a gain $K$ to raise the magnitude curve up. The gain is determined in such a way that the magnitude curve crosses the $0 \mathrm{~dB}$ line at the desired bandwidth. The gain is computed using (14) as follows:

$$
\begin{aligned}
& \left|G_{I, \text { OL_uncompen }}(j)\right| \\
& \quad=\frac{K}{78 \times 10^{-9} j^{2}+1.573 \times 10^{-3} j+0.821 \times 10^{-3}},
\end{aligned}
$$

15707.96

$$
\begin{array}{r}
K \frac{K}{\left(78 \times 10^{-9} j^{2}+1.573 \times 10^{-3} j+0.821 \times 10^{-3}\right)} . \\
K=31.12 .
\end{array}
$$

Multiplying (13) with the gain $K$ gives (15) which is used for plotting the phase and magnitude curves of the gaincompensated open-loop transfer function:

$$
\begin{aligned}
& G_{I, \text { OL_compen_gain }}(s) \\
& \quad=\frac{31.12}{78 \times 10^{-9} s^{2}+1.573 \times 10^{-3} s+0.821 \times 10^{-3}} .
\end{aligned}
$$

Figure 8 shows the magnitude and phase curves of the gain-compensated open-loop transfer function of the inner current control loop. From Figure 8, it can be observed that

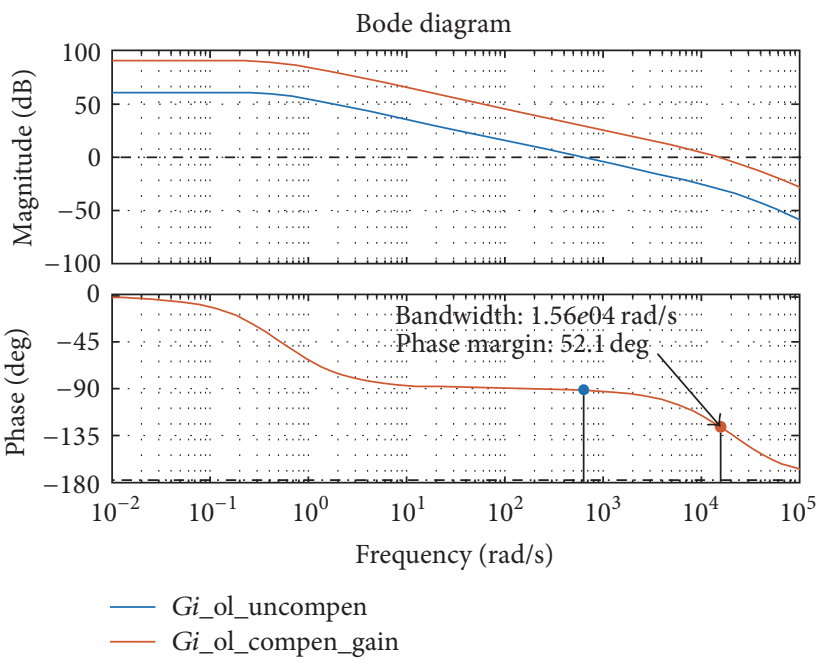

FIGURE 8: Bode plot of the gain-compensated transfer function.

the bandwidth requirement has been met. The phase margin at the desired bandwidth is $52.1^{\circ}$. To obtain the desired phase margin of $39.52^{\circ}$, a phase-lag compensator is needed to shift the phase curve down.

(2) Phase-Lag Compensator Design. The first step of designing a phase-lag compensator is to compute the phase attenuation needed to obtain the desired phase margin. This is done by subtracting the current phase margin from the desired phase margin as follows.

$$
\text { Phase attenuation }=\mathrm{PM}_{\text {desired }}-\mathrm{PM}_{\text {current }}=-12.58^{\circ} .
$$

The phase attenuation is used to locate the pole $p_{c}$ and zero $z_{c}$ of the phase-lag compensator by calculating the frequency $[\mathrm{Hz}]$ where the pole and zero will be located using the following equation [31]:

$$
\begin{aligned}
& f_{z}=f_{\mathrm{BW}} \sqrt{\frac{1-\sin (\text { phase-attenuation })}{1+\sin (\text { phase-attenuation })}}, \\
& f_{p}=f_{\mathrm{BW}} \sqrt{\frac{1+\sin (\text { phase-attenuation })}{1-\sin (\text { phase-attenuation })}},
\end{aligned}
$$

where $f_{\mathrm{BW}}$ is the bandwidth frequency, which in this study is equal to $2500 \mathrm{~Hz}$. Therefore, $f_{p}$ and $f_{z}$ are equal to $3119.39 \mathrm{~Hz}$ and $2003.59 \mathrm{~Hz}$, respectively. The angular frequencies $\omega_{p}$ and $\omega_{z}$ where the pole and zero of the phase-lag compensator are located are equal to $19599.7 \mathrm{rad} / \mathrm{s}$ and $12588.9 \mathrm{rad} / \mathrm{s}$, respectively. Therefore, the transfer function of the phase-lag compensator is given by the following equation [31]:

$$
\begin{aligned}
G_{\mathrm{lag}}(s)=G_{\mathrm{co}}\left(\frac{\tau_{\mathrm{lag}} s+1}{\alpha \tau_{\mathrm{lag}} s+1}\right)=\frac{6.366 \times 10^{-5} s+1.248}{7.943 \times 10^{-5} s+1} \\
\quad \text { where; } \alpha=\frac{\omega_{z}}{\omega_{p}}=\frac{19599.71}{12588.93}=1.557, G_{\mathrm{co}}=\sqrt{\alpha}=\sqrt{1.557}=1.248, \tau_{\mathrm{lag}}=\frac{1}{\omega_{z}}=\frac{1}{19599.71}=0.05 \times 10^{-3} .
\end{aligned}
$$


The phase-lag compensator is applied to the gain-compensated system, and hence multiplying (15) by (17) gives
(18) which represents the transfer function of the phase-lag compensated system for the inner current control loop:

$$
\begin{aligned}
& G_{I, \text { OL_compen_lag }}(s)=G_{I, \mathrm{OL}_{-} \text {compen_gain }}(s) \times G_{\text {lag }}(s), \\
& G_{I, \text { OL_compen_lag }}(s)=\frac{1.97 \times 10^{-3} s+38.68}{6.25 \times 10^{-12} s^{3}+2.036 \times 10^{-7} s^{2}+1.573 \times 10^{-3} s+0.821 \times 10^{-3}} .
\end{aligned}
$$

Figure 9 shows the magnitude and phase curves of the phase-lag compensated open-loop transfer function of the inner current control loop.

It is observed that the phase-lag compensator shifted the phase curve down to yield the phase margin of $39.5^{\circ}$. The bandwidth is maintained at $1.57 \times 10^{4} \mathrm{rad} / \mathrm{s}(2500 \mathrm{~Hz})$. Therefore, the phase margin and bandwidth design specifications have been met.

Figures 10(a), 10(b), and 10(c) show the step-response curves indicating the peak response, settling time, and rise time of the uncompensated, gain-compensated, and phaselag compensated closed-loop transfer function of the inner stator current control loop.

Figure 10(a) shows that the overshoot of the gaincompensated system is $16 \%$, while the overshoot of the phaselag compensated system is $29.5 \%$. Therefore, the percentage overshoot of the gain-compensated system falls within the desired overshoot of 25\%. Figure 10(b) shows that gain $K$ reduced the settling time of the uncompensated system from $6 \mathrm{~ms}$ to $0.4 \mathrm{~ms}$. However, the phase-lag compensator reduced the settling time of the gain-compensated system to $0.6 \mathrm{~ms}$, which is within the desired settling time of $0.856 \mathrm{~ms}$.

This illustrates that the settling time design specification of the inner current controller has been achieved. Figure 10 (c) shows that gain $K$ reduced the rise time of the uncompensated system from $3.34 \mathrm{~ms}$ to $0.0829 \mathrm{~ms}$ and this speeds up the system response. However, the phase-lag compensator increased the gain-compensated system's rise time to $0.079 \mathrm{~ms}$ which is within the desired rise time of $0.127 \mathrm{~ms}$. This illustrates that the rise time design specification of the inner current controller has also been achieved.

3.2.4. Design Specifications of the Outer Control Loop. The outer control loops are expected to be slower than the inner current control loops. Therefore, the bandwidth of the outer control loops is taken to be $625 \mathrm{~Hz}(3926.99 \mathrm{rad} / \mathrm{s})$, which is one-fourth of the inner current control loops' switching frequency. Moreover, the slower outer loop needs to have a smaller overshoot as compared to the fast inner current controllers loop to get rid of as many oscillations in the controller as possible, thereby enhancing the stability of the entire system. Therefore, the percentage overshoot is taken to be $5 \%$. Therefore, the damping ratio and phase margin calculated using (4) and (5) are equal to 0.69 and $57.85^{\circ}$, respectively. Furthermore, the settling time and rise time of the inner current controller calculated using (7) and (8) are equal to $1.2 \mathrm{~ms}$ and $0.42 \mathrm{~ms}$, respectively.
(1) Derivation of the Transfer Functions: Maximum Power Point Tracking Control Loop. MPPT is achieved when the WT operates at optimal $C_{p}\left(C_{p_{-} \text {opt }}\right)$ and optimal tip speed ratio $\lambda_{\text {opt }}$. Therefore, the rotor speed $\omega_{r}$ needs to be varied relative to the change in wind speed $v_{w}$ to keep the tip speed ratio at $\lambda_{\text {opt }}$. The equation relating the optimal power to the optimal rotor speed $\omega_{r_{-} \text {opt }}, C_{p_{-} \text {opt }}$, and $\lambda_{\text {opt }}$. is derived by substituting (2) into (1) as illustrated by the following equation [3]:

$$
P_{\mathrm{opt}}=\frac{1}{2} \rho A C_{P_{\mathrm{opt}}}\left(\frac{\omega_{r_{\mathrm{opt}}} \times r}{\lambda_{\mathrm{opt}}}\right)^{3} \text {. }
$$

The output power $P_{\mathrm{opt}}$ from the MPPT stage serves as an input into the outer active power control loop. The output of the outer controller block is the $d$-component of the reference current fed into the inner current control loop. Figures 11(a) and 11(b) show the initial and final active power control loops.

Using the $d q$ axis theory, the instantaneous real power and reactive power of the PMSG are described by the following equation [49]:

$$
\begin{gathered}
P_{\text {gen }}=\frac{3}{2}\left(V_{s d} i_{s d}+V_{s q} i_{s q}\right) ; \\
Q_{\text {gen }}=\frac{3}{2}\left(V_{s q} i_{s d}-V_{s d} i_{s q}\right) .
\end{gathered}
$$

In stator voltage reference frame, $d$-axis of the synchronous reference frame is aligned with the stator voltage vector. Therefore, the stator voltage only has the $d$-axis component $V_{s d}$, while the $q$-axis component $V_{s q}$ is set to zero. Therefore, (20) becomes

$$
\begin{gathered}
P_{\text {gen }}=\frac{3}{2} V_{s d} i_{s d} \\
Q_{\text {gen }}=-\frac{3}{2} V_{s d} i_{s q} .
\end{gathered}
$$

Therefore, the system transfer function in Figure 11(a) is given by the following equation:

$$
\frac{P_{\text {gen }}}{i_{s d}}=\frac{3}{2} V_{s d} .
$$

From Figure 11(b), the open-loop transfer function of the MPPT control loop is given by the following equation:

$$
G_{P, \mathrm{ol}}(s)=G_{C, p}(s) \times G_{C, \mathrm{cl}}(s) \times \frac{3}{2} V_{s d} .
$$



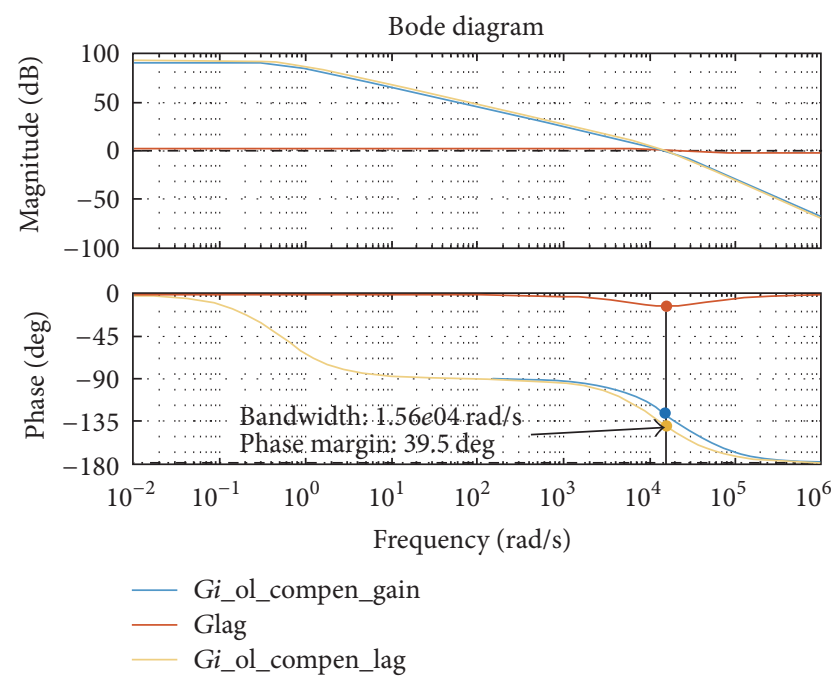

FIGURE 9: Bode plot of the phase-lag compensated transfer function.

(2) The Uncompensated MPPT Control Loop. The open-loop transfer function used to plot the magnitude and phase curves of the outer MPPT control loop is given by (25). It is derived by substituting the converter's voltage of $620.62 \mathrm{~V}$ and the closed-loop transfer function $G_{I, C L}(s)$ of the phaselag compensated inner current loop given by (24) into (23):

$$
\begin{aligned}
& G_{I, \mathrm{CL}}(s) \\
& =\frac{2.23 \times 10^{-3} s+43.52}{6.96 \times 10^{-12} s^{3}+2.27 \times 10^{-7} s^{2}+3.99 \times 10^{-3} s+43.52}, \\
& G_{P, \text { OL_uncompen }}(s)=G_{P, \mathrm{ol}}(s) \times G_{I, \mathrm{CL}}(s), \\
& G_{P, \text { OL_uncompen }}(s) \\
& =\frac{\left(4.149 s+8.102 \times 10^{4}\right) \times G_{C, P}(s)}{1.393 \times 10^{-11} s^{3}+4.55 \times 10^{-7} s^{2}+7.98 \times 10^{-3} s+87.03} .
\end{aligned}
$$

Figure 12 shows the bode plot of the uncompensated open-loop transfer function of the MPPT control loop. That is, $G_{C, P}(s)=1$.
From Figure 12, it is observed that the phase margin and bandwidth of the uncompensated system are $1.38^{\circ}$ and $5.46 \times 10^{5} \mathrm{rad} / \mathrm{s}$, respectively. The bandwidth is much higher than the desired value and the phase margin is very small. To reduce the bandwidth, a phase-lag compensator is needed to drop the magnitude curve down so that it crosses the $0 \mathrm{~dB}$ line at the desired bandwidth of $3926.99 \mathrm{rad} / \mathrm{s}(625 \mathrm{~Hz})$.

(3) Phase-Lag Compensator Design. The first step is to identify the gain magnitude corresponding to the desired bandwidth on the magnitude curve. The gain magnitude at the desired bandwidth is $59.7 \mathrm{~dB}$ as shown in Figure 13.

The magnitude at the desired crossover frequency is then used to calculate the attenuation $\alpha$ needed to shift the magnitude curve down. The attenuation is used to locate the pole and zero of the phase-lag compensator and it is calculated using the following equation [31]:

$$
\alpha=10^{\text {gain } / 10}=10^{59.7 / 10}=933254.30 .
$$

The frequencies where the pole $p_{c}$ and zero $z_{c}$ will be located are calculated using the following equation:

$$
\begin{aligned}
& z_{c}=\omega_{\text {bandwidth }} \times \sqrt{\alpha}, \\
& p_{c}=\frac{z_{c}}{\alpha} .
\end{aligned}
$$

Therefore, the pole $p_{c}$ and zero $z_{c}$ of the phase-lag compensator with a bandwidth $\omega_{\text {bandwidth }}$ of $3926.99 \mathrm{rad} / \mathrm{s}$ and attenuation $\alpha$ of 933254.30 are located at $3.79 \times 10^{6} \mathrm{rad} / \mathrm{s}$ and $4.065 \mathrm{rad} / \mathrm{s}$, respectively. The transfer function of the phase-lag compensator is given by the following equation [31]:

$$
G_{\text {lag }}(s)=\frac{\left(s / z_{c}+1\right)}{\left(s / p_{c}+1\right)}=\frac{2.636 \times 10^{-7} s+1}{0.246 s+1} .
$$

Multiplying (25) by (28) gives (29) which represents the open-loop transfer function of the phase-lag compensated system:

$$
\begin{aligned}
& G_{P, \text { OL_compen_lag }}(s)=G_{P, \text { OL_uncompen }}(s) \times G_{\text {lag }}(s) \\
& G_{P, \text { OL_compen_lag }}(s)=\frac{1.09 \times 10^{-6} s^{2}+4.17 s+8.102 \times 10^{4}}{3.427 \times 10^{-12} s^{4}+1.118 \times 10^{-7} s^{3}+1.96 \times 10^{-3} s^{2}+21.42 s+87.03} .
\end{aligned}
$$

Figure 14 shows the magnitude and phase curves of the phase-lag compensated open-loop transfer function of the MPPT control loop.

From Figure 14, it is observed that phase-lag compensator shifted the magnitude curve down by $60.6 \mathrm{~dB}$ at the bandwidth of $3.93 \times 10^{3} \mathrm{rad} / \mathrm{s}$, and hence the bandwidth design specification has been met. The phase margin at the desired bandwidth is $80.6^{\circ}$. Therefore, a second phase-lag compensator is needed to shift the phase curve down to obtain the desired phase margin of $57.85^{\circ}$. 


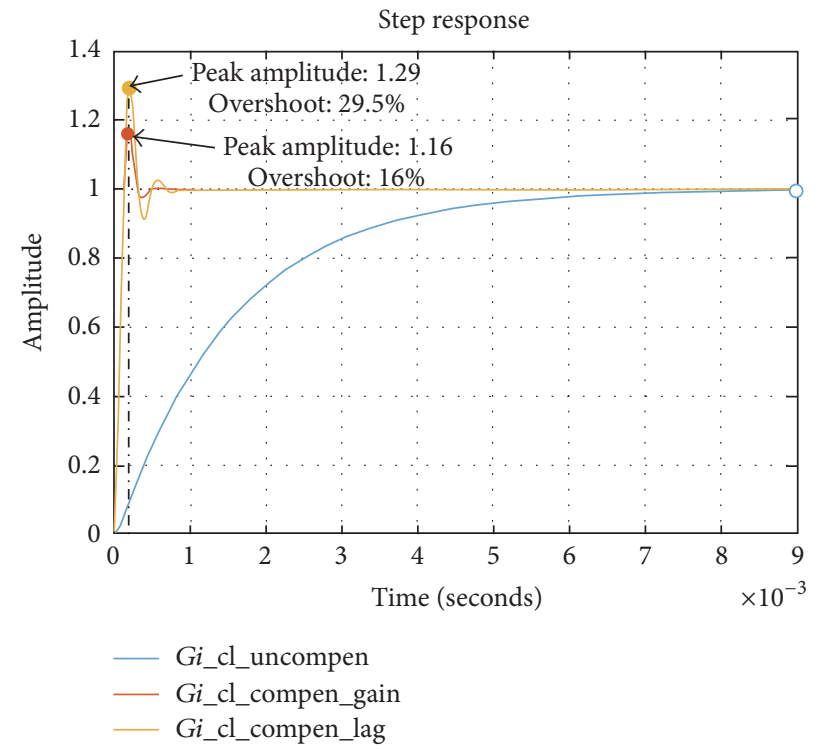

(a)

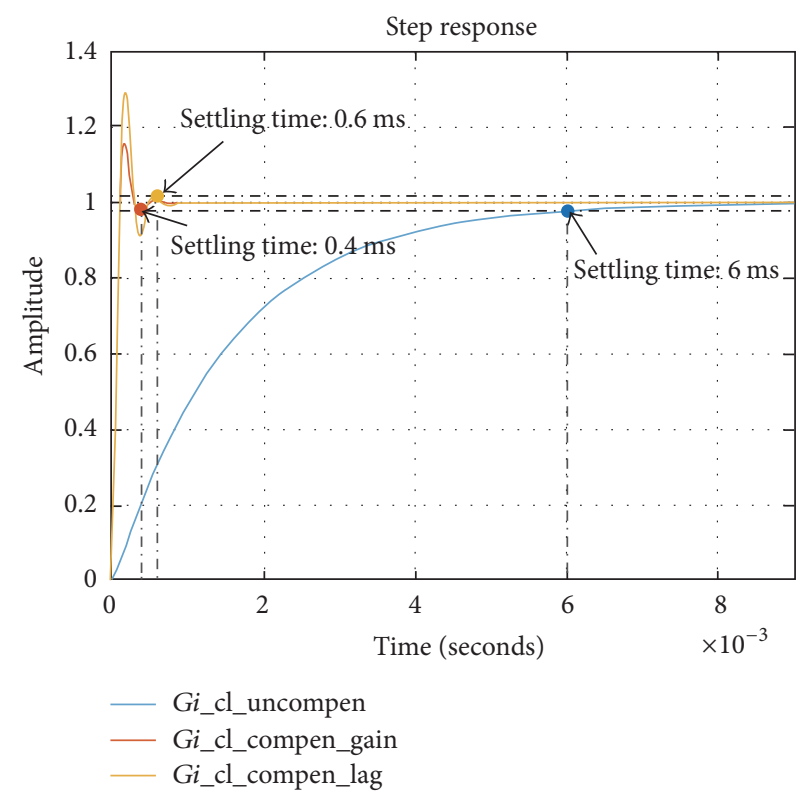

(b)

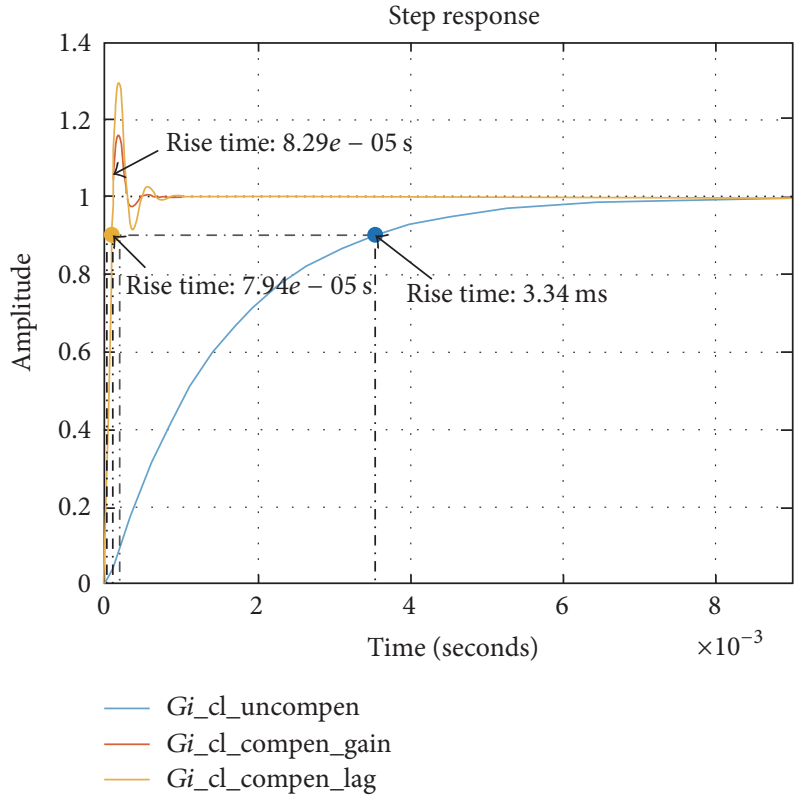

(c)

FIGURE 10: Step response of the inner current controller's closed-loop transfer function: (a) peak response, (b) settling time, and (c) rise time.

(4) The Second Phase-Lag Compensator Design. The first step is to compute the phase attenuation needed to obtain the desired phase margin by subtracting the current phase margin from the desired phase margin as follows.

$$
\text { Phase attenuation }=\mathrm{PM}_{\text {desired }}-\mathrm{PM}_{\text {current }}=-22.75^{\circ} \text {. }
$$

Therefore, the frequency $[\mathrm{Hz}]$ where the pole $p_{c}$ and zero $z_{c}$ calculated using (16) and the phase attenuation are equal to $415.64 \mathrm{~Hz}$ and $939.81 \mathrm{~Hz}$, respectively. Moreover, the angular frequencies $\omega_{p}$ and $\omega_{z}$ where the pole and zero of the phaselag compensator will be located are equal to $2611.54 \mathrm{rad} / \mathrm{s}$ and $5905 \mathrm{rad} / \mathrm{s}$, respectively.
The transfer function of the phase-lag compensator is given by the following equation:

$$
\begin{aligned}
G_{\operatorname{lag}_{2}}(s) & =G_{\mathrm{co}}\left(\frac{\tau_{\mathrm{lag}} s+1}{\alpha \tau_{\mathrm{lag}} s+1}\right) \\
& =\frac{0.255 \times 10^{-3} s+1.504}{0.383 \times 10^{-3} s+1} .
\end{aligned}
$$

The second phase-lag compensator is applied to the phase-lag compensated system, and hence multiplying (29) 


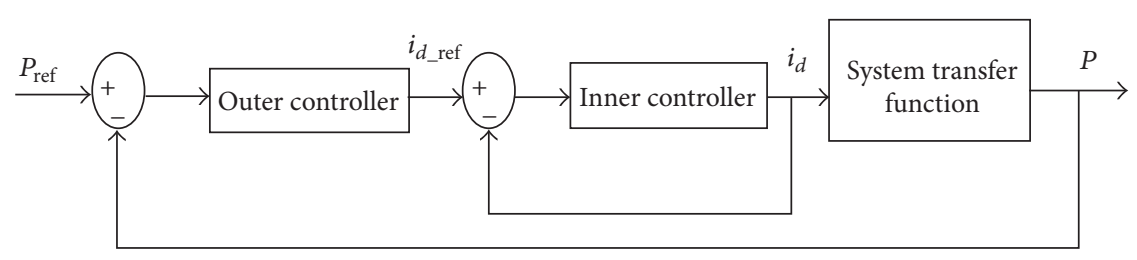

(a)

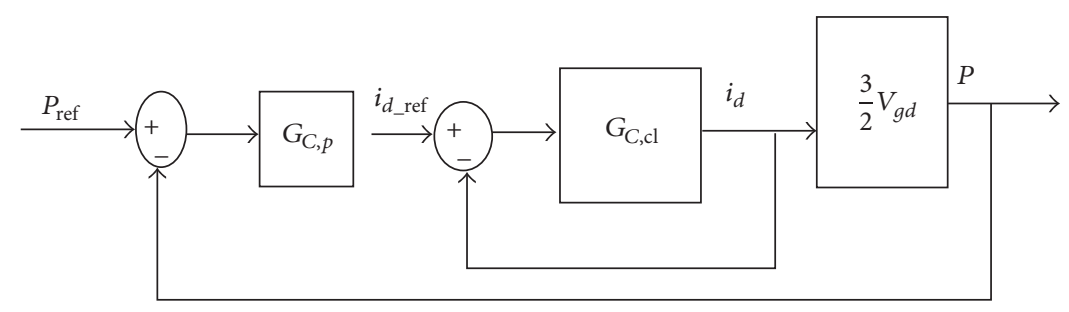

(b)

FIgURE 11: MPPT control loop: (a) initial control loop and (b) final control loop.

by (30) gives the transfer function of the phase-lag-lag compensated system as follows:

$$
\begin{aligned}
& G_{P, \mathrm{OL} \_ \text {compen_2lag }}(s)=G_{P, \mathrm{OL} \_ \text {compen_lag }}(s) \times G_{\operatorname{lag}_{2}}(s) \\
& G_{P, \mathrm{OL} \_ \text {compen_2lag }}(s)=\frac{2.784 \times 10^{-10} s^{3}+1.063 \times 10^{-3} s^{2}+26.9 s+1.218 \times 10^{5}}{1.312 \times 10^{-15} s^{5}+4.625 \times 10^{-11} s^{4}+8.633 \times 10^{-7} s^{3}+0.0102 s^{2}+21.45 s+87.03}
\end{aligned}
$$

Figure 15 shows the bode plot of the MPPT controller's open-loop transfer function compensated with the two phase-lag compensators. From Figure 15, it is observed that the second phase-lag compensator shifted the phase curve down to yield the phase margin of $57.9^{\circ}$. The bandwidth is maintained at $3.92 \times 10^{3} \mathrm{rad} / \mathrm{s}(625 \mathrm{~Hz})$. Therefore, the phase margin and bandwidth design specifications of the outer controller have been met.

Figures 16(a), 16(b), and 16(c) show the step-response curve indicating the peak response, settling time, and rise time of the uncompensated, the phase-lag compensated, and second phase-lag compensated closed-loop transfer function of the outer MPPT control loop, respectively.

Figure 16(a) shows that the phase-lag compensators reduced the percentage overshoot of the uncompensated system from $96.5 \%$ to $12.1 \%$. Figure 16 (b) shows that the first phase-lag compensator increased the settling time of the uncompensated system from $0.593 \mathrm{~ms}$ to $0.956 \mathrm{~ms}$. Moreover, the second phase-lag compensator further increased the settling time of the phase-lag compensated system to $1.3 \mathrm{~ms}$, which is close to the desired settling time of $1.2 \mathrm{~ms}$. Figure 16(c) shows that the rise time of the uncompensated system is $1.93 \mu \mathrm{s}$. The first phase-lag compensator increased the system's rise time to $0.485 \mathrm{~ms}$, while the second phaselag compensator increased the rise time to $0.297 \mathrm{~ms}$ which is within the desired rise time of $0.42 \mathrm{~ms}$. This shows that the rise time and settling time design specifications of the outer controller have been met.

\section{Results and Discussions}

The proposed wind turbine conversion system has been implemented in PSIM software package as shown in Figure 17.

Tables 1 and 2 show the parameters of a typical variable speed wind turbine driven by a 2 MW PMSG. This wind turbine is available in the industry and its parameters fall within the same order of magnitude with the wind turbines of the same rated power manufactured by Vestas and Gamesa.

The wind speed is varied to analyze how the system reacts to the change in wind speed. Figure 18 shows the variation in wind speed from the wind turbine's cut-in wind speed $(4 \mathrm{~m} / \mathrm{s})$ to the rated wind speed $(13 \mathrm{~m} / \mathrm{s})$ at $0.6 \mathrm{~s}$ up until $18 \mathrm{~m} / \mathrm{s}$, approaching the WT's cut-out wind speed (see Table 1).

Figures 19(a), 19(b), and 19(c) show the rotor angular speed, the aerodynamic power, and aerodynamic torque, respectively.

Figure 19(a) shows that the rotor angular speed increases as the wind speed increases. Moreover, at the rated wind speed $(13 \mathrm{~m} / \mathrm{s})$, the measured rotor speed is equal to the rated rotor speed, which is $2.356 \mathrm{rad} / \mathrm{s}$. Figure 19(b) shows that when the wind speed is below the WT's rated wind speed $(13 \mathrm{~m} / \mathrm{s})$, the power generated from the WT tracks the optimal power curve to ensure MPPT. When the wind speed is equal to the WT's rated wind speed, the power generated is equal to $2 \mathrm{MW}$ which is the WT's rated power. Moreover, as the wind speed increases further above the WT's rated wind 

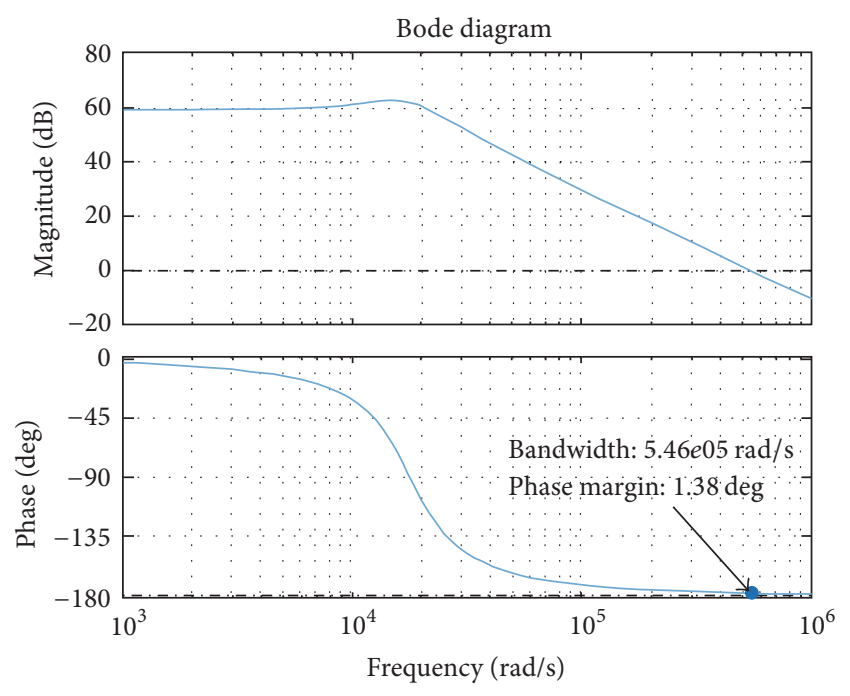

Gp_ol_uncompen

FIGURE 12: Bode plot of the uncompensated transfer function.

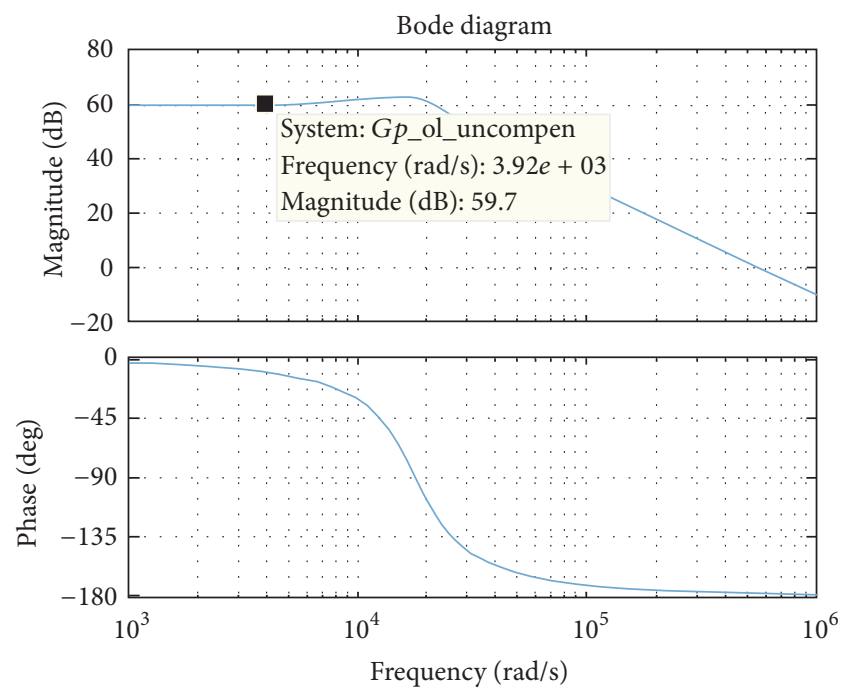

FIGURE 13: Gain magnitude at the desired bandwidth.

TABLE 1: Wind turbine parameters.

\begin{tabular}{lc}
\hline Parameters & Values \\
\hline Rated power $(\mathrm{MW})$ & 2 \\
Cut-in wind speed $(\mathrm{m} / \mathrm{s})$ & 4 \\
Rated wind speed $(\mathrm{m} / \mathrm{s})$ & 13 \\
Cut-out wind speed $(\mathrm{m} / \mathrm{s})$ & 25 \\
Number of rotor blades & 3 \\
Rotor area $\left(\mathrm{m}^{2}\right)$ & 4587 \\
Rotor diameter $(\mathrm{m})$ & 76.42 \\
Air density $\left(\mathrm{kg} / \mathrm{m}^{2}\right)$ & 1.225 \\
Optimal power coefficient $C p$ & 0.4 \\
\hline
\end{tabular}

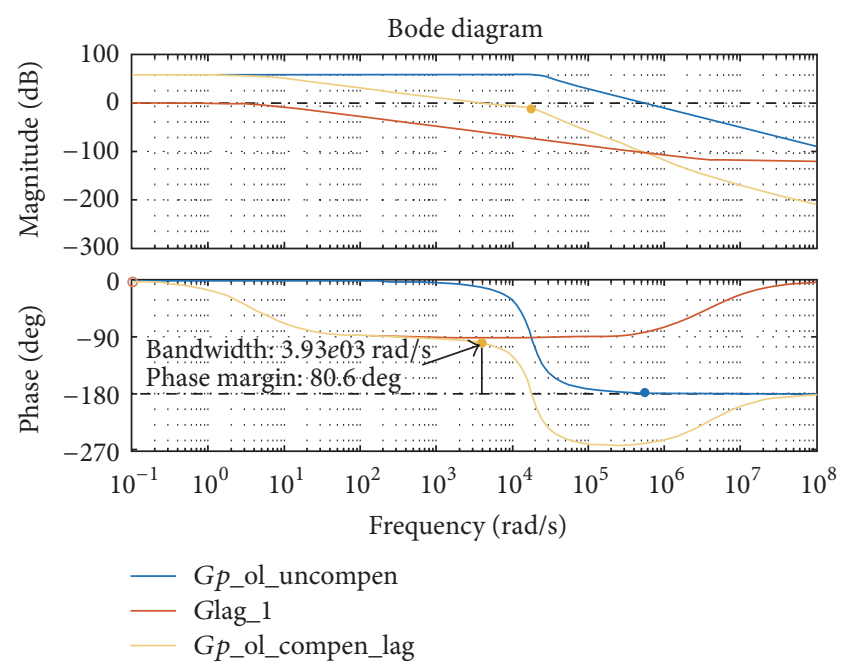

FIGURE 14: Bode plot of the phase-lag compensated transfer function.

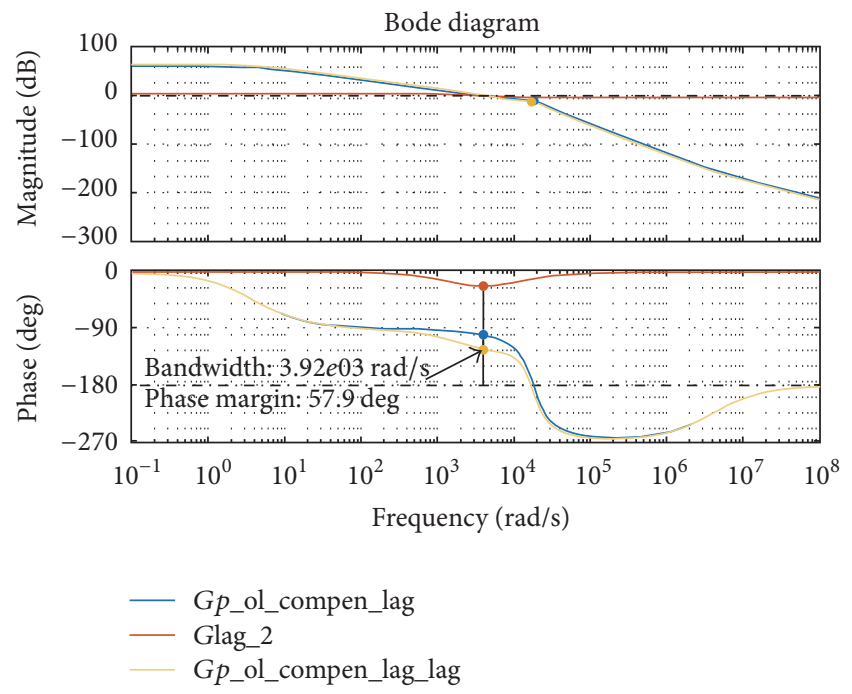

FIGURE 15: Bode plot of the transfer function compensated with the two phase-lag compensators.

TABLE 2: PMSG parameters.

\begin{tabular}{lc}
\hline Parameters & Value \\
\hline Generator type & PMSG \\
Rated mechanical power, $P(\mathrm{MW})$ & 2 \\
Rated apparent power, $S(\mathrm{MVA})$ & 2.24 \\
Rated $L$ - $L$ voltage, $V_{L-L}(\mathrm{~V})$ & $690(\mathrm{rms})$ \\
Rated power factor, pf & 0.89 \\
Rated rotor speed, $\omega_{\text {rated }}(\mathrm{rpm})$ & 22.5 \\
Pole pairs, $n_{p}$ & 26 \\
Rated mechanical torque $(\mathrm{kNm})$ & 848.83 \\
Flux linkage, $\psi_{f}(\mathrm{~Wb})$ & 4.971 \\
Stator winding resistance, $R_{s}(\mathrm{~m} \Omega)$ & 0.821 \\
Stator $d$-axis inductance, $L_{d s}(\mathrm{mH})$ & 1.573 \\
Stator $q$-axis inductance, $L_{q s}(\mathrm{mH})$ & 1.573 \\
\hline
\end{tabular}




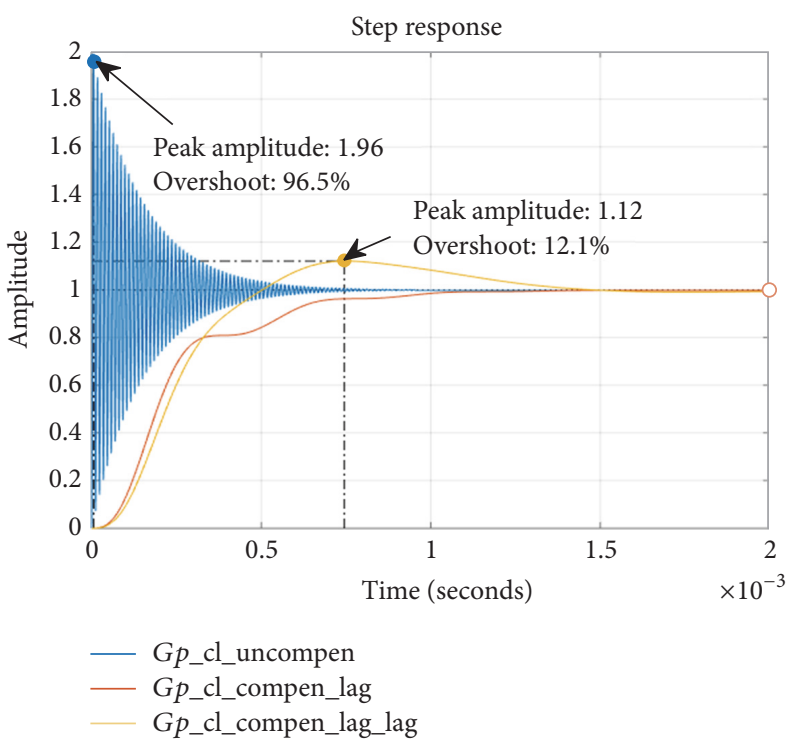

(a)

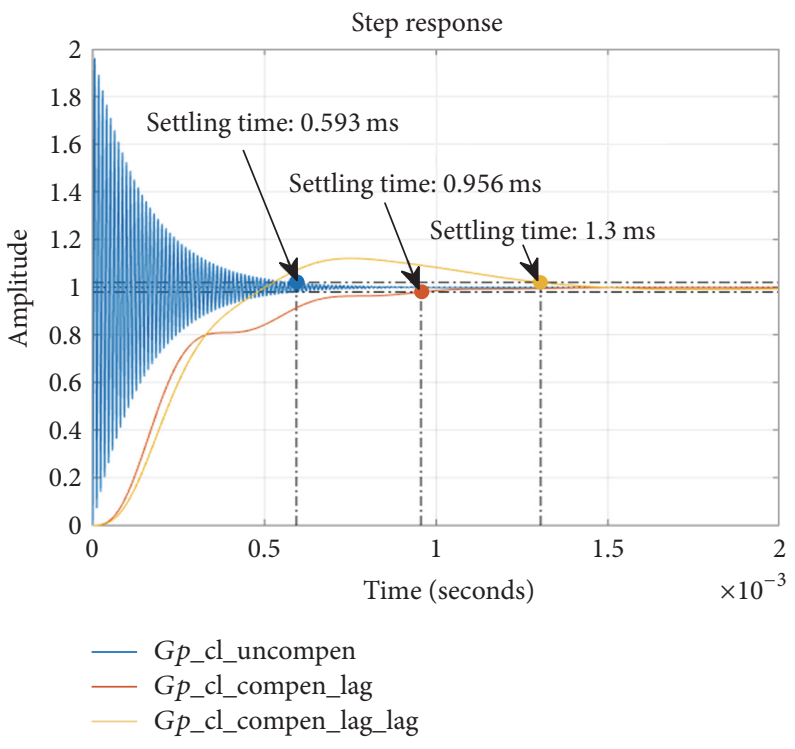

(b)

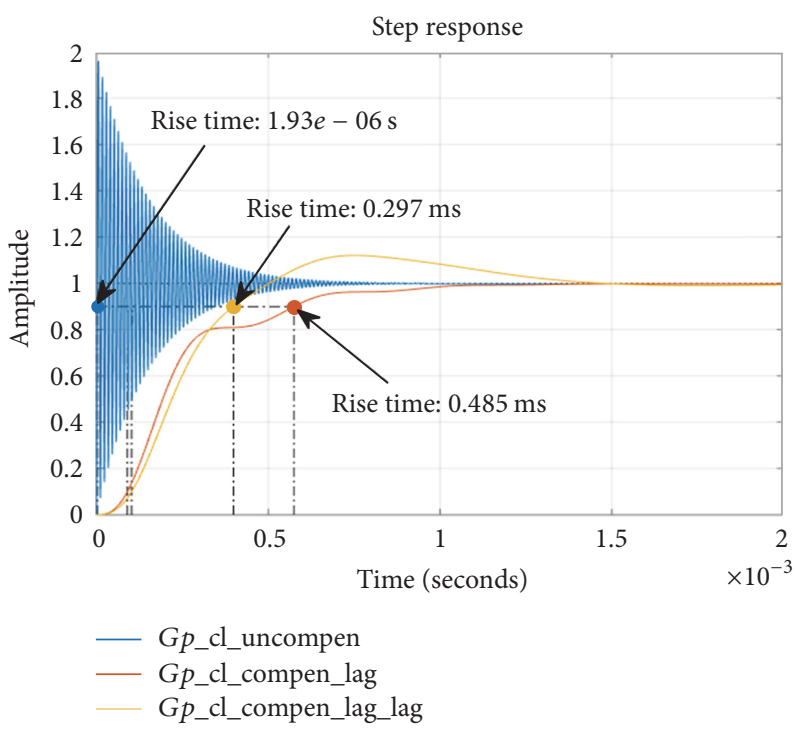

(c)

FIGURE 16: Step response of the MPPT controller's closed-loop transfer function: (a) peak response, (b) settling time, and (c) rise time.

speed, the generated power remains equal to the rated power. Figure 19(c) shows that, during the MPPT stage, the generated torque closely tracks the optimal torque curve until the rated WT's rated torque. At the rated power ( $2 \mathrm{MW})$, the torque is equal to the WT generator's rated torque of $849 \mathrm{kNm}$.

\section{Conclusions}

This research investigation serves as a starting point of modularly expanding the already existing mini wind power plant in Namibia by thoroughly analyzing and designing the rotor speed controller of a $2 \mathrm{MW}$ PMSG-based WECS to achieve MPPT.

The wind turbine system components and the MPPT controller were successfully implemented in PSIM software package. The design and stability analysis of the generatorside converter controller which comprises a phase-lag compensator was carried out in MATLAB software package using bode plots and step-response curves. Based on the simulation results, it was observed that the MPPT controller enabled the power generated from the WT to closely track the optimal power curve to ensure maximum power generation when the wind speed is less than the WT's rated wind speed $(13 \mathrm{~m} / \mathrm{s})$. It was also observed that when the wind speed is equal to the WT's rated wind speed, the aerodynamic power generated is equal to $2 \mathrm{MW}$ which is the WT's rated power. The MPPT controller also enabled the generated torque to closely track the optimal torque curve when the wind speed was lower than the WT's rated wind speed. 


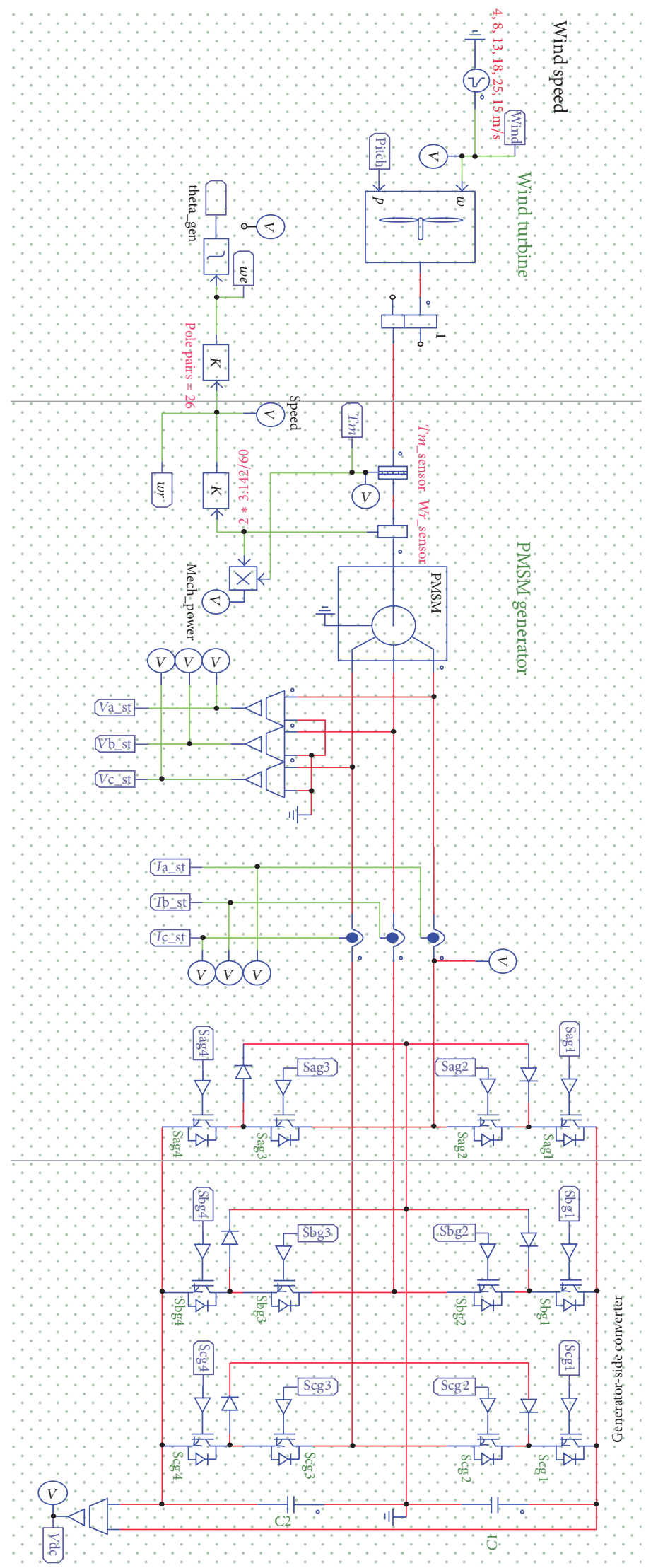

FIGURE 17: Proposed wind energy conversion system. 


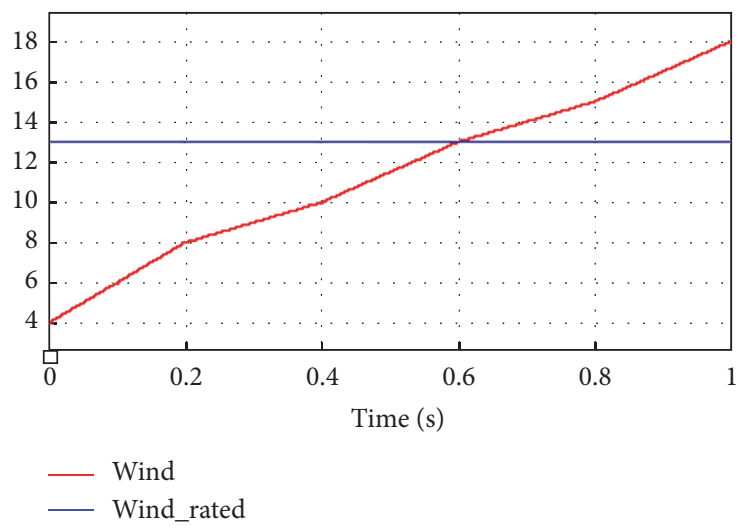

Figure 18: Wind speed model.

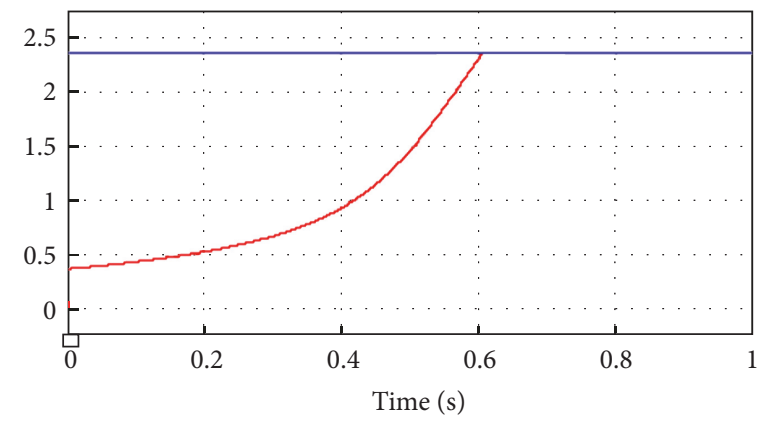

$W r$
$-W r$ rated

(a)

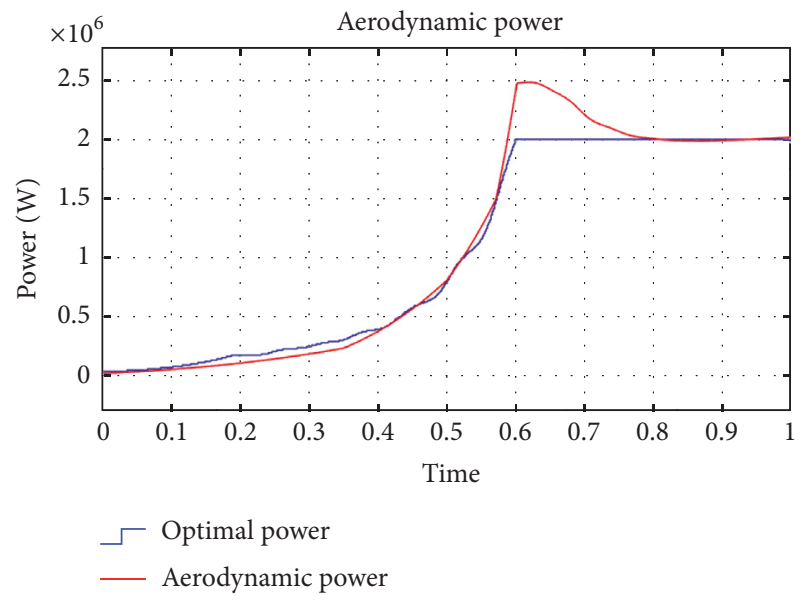

(b)

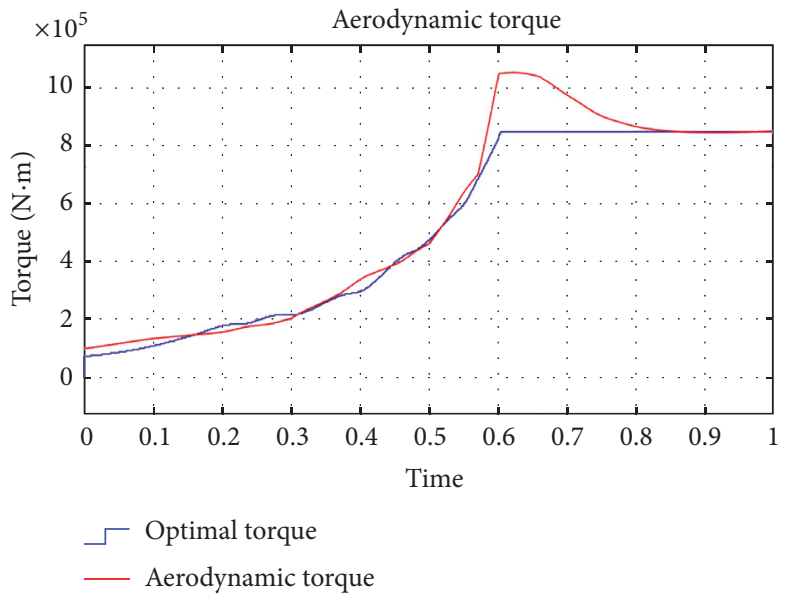

(c)

FIGURE 19: MPPT control: (a) rotor angular speed, (b) aerodynamic power, and (c) aerodynamic torque.

\section{Conflicts of Interest}

The authors declare that there are no conflicts of interest regarding the publication of this paper.

\section{Acknowledgments}

This research is supported by the Eskom Power Plant Engineering Institute (EPPEI) Program. 


\section{References}

[1] Z. Zhang, Y. Zhao, W. Qiao, and L. Qu, "A discrete-time direct torque control for direct-drive PMSG-based wind energy conversion systems," IEEE Transactions on Industry Applications, vol. 51, no. 4, pp. 3504-3514, 2015.

[2] G. M. J. Herbert, S. Iniyan, E. Sreevalsan, and S. Rajapandian, "A review of wind energy technologies," Renewable and Sustainable Energy Reviews, vol. 11, no. 6, pp. 1117-1145, 2007.

[3] S. M. Tripathi, A. N. Tiwari, and D. Singh, "Grid-integrated permanent magnet synchronous generator based wind energy conversion systems: a technology review," Renewable and Sustainable Energy Reviews, vol. 51, article 4598, pp. 1288-1305, 2015.

[4] A. L. Soriano, W. Yu, and J. J. Rubio, "Modeling and control of wind turbine," Mathematical Problems in Engineering, vol. 2013, Article ID 982597, p. 7, 2013.

[5] B. Snyder and M. J. Kaiser, "Ecological and economic costbenefit analysis of offshore wind energy," Renewable Energy, vol. 34, no. 6, pp. 1567-1578, 2009.

[6] Z. Jinhua, L. Yongqian, D. Infield, M. Yuanchi, C. Qunshi, and T. De, "Optimal power dispatch within wind farm based on two approaches to wind turbine classification," Renewable Energy, vol. 102, pp. 487-501, 2017.

[7] T. Ackermann and L. Söder, "Wind energy technology and current status: a review," Renewable and Sustainable Energy Reviews, vol. 4, no. 4, pp. 315-374, 2000.

[8] P. S. Barendse and P. Pillay, "A doubly-fed induction generator drive for a wind energy conversion system," Transactions of the South African Institute of Electrical Engineers, vol. 97, pp. 274280, 2006.

[9] J. O. Okoronkwo, O. Ojo, and I. Davidson, "Design considerations of the Katsina wind farm in Nigeria," in Proceedings of the IEEE PES Power Africa Conference, pp. 251-253, Livingstone, Zambia, June 2016.

[10] A. Edrisian, A. Goudarzi, I. E. Davidson, A. Ahmadi, and G. K. Venayagamoorthy, "Enhancing SCIG-based wind turbine generator performance through reactive power control," in Proceedings of the Clemson University Power Systems Conference (PSC '15), pp. 1-8, Clemson, SC, USA, March 2015.

[11] Y. Zhang, Z. Liu, Z. Yang, and H. Si, "Robust control of wind turbines by using singular perturbation method and linear parameter varying model," Journal of Control Science and Engineering, vol. 2016, Article ID 2830736, 2016.

[12] T. Li, A. J. Feng, and L. Zhao, "Neural network compensation control for output power optimization of wind energy conversion system based on data-driven control," Journal of Control Science and Engineering, vol. 2012, Article ID 736586, 8 pages, 2012.

[13] M. R. Islam, Y. Guo, and J. Zhu, "A review of offshore wind turbine nacelle: technical challenges, and research and developmental trends," Renewable and Sustainable Energy Reviews, vol. 33, pp. 161-176, 2014.

[14] Q. Xu, C. Zhang, L. Zhang, and C. Wang, "Multiobjective optimization of PID controller of PMSM," Journal of Control Science and Engineering, vol. 2014, Article ID 471609, 2014.

[15] A. Giallanza, M. Porretto, L. Cannizzaro, and G. Marannano, "Analysis of the maximization of wind turbine energy yield using a continuously variable transmission system," Renewable Energy, vol. 102, pp. 481-486, 2017.
[16] J. A. Baroudi, V. Dinavahi, and A. M. Knight, "A review of power converter topologies for wind generators," Renewable Energy, vol. 32, no. 14, pp. 2369-2385, 2007.

[17] S. Ravichandran, K. D. R. Pandu, and S. G. Bharathidasan, "Coordinated controller design of grid-connected variablespeed wind energy conversion system with model-based predictive control using response surface methodology," Electric Power Components and Systems, vol. 42, no. 11, pp. 1107-1120, 2014.

[18] Z. Chen, J. M. Guerrero, and F. Blaabjerg, "A review of the state of the art of power electronics for wind turbines," IEEE Transactions on Power Electronics, vol. 24, no. 8, pp. 1859-1875, 2009.

[19] M. Chinchilla, S. Arnalte, J. C. Burgos, and J. L. Rodríguez, "Power limits of grid-connected modern wind energy systems," Renewable Energy, vol. 31, no. 9, pp. 1455-1470, 2006.

[20] A. M. Massoud, S. Ahmed, A. S. Abdel-Khalik, A. A. Elserougi, and K. H. Ahmed, "Control of power converters for emerging applications of power electronics," Journal of Control Science and Engineering, vol. 2016, Article ID 9235283, 2 pages, 2016.

[21] Y. Yang, K.-T. Mok, S.-C. Tan, and S. Y. R. Hui, "Nonlinear dynamic power tracking of low-power wind energy conversion system," IEEE Transactions on Power Electronics, vol. 30, no. 9, pp. 5223-5236, 2015.

[22] Y. Errami, M. Ouassaid, and M. Maaroufi, "Optimal power control strategy of maximizing wind energy tracking and different operating conditions for permanent magnet synchronous generator wind farm," Energy Procedia, vol. 74, pp. 477-490, 2015.

[23] M. Nasiri, J. Milimonfared, and S. H. Fathi, "Modeling, analysis and comparison of TSR and OTC methods for MPPT and power smoothing in permanent magnet synchronous generator-based wind turbines," Energy Conversion and Management, vol. 86, pp. 892-900, 2014.

[24] S. Bowes, "A novel harmonic elimination PWM strategy," in Proceedings of the 7th International Conference on Power Electronics and Variable Speed Drives, pp. 426-432, London, UK.

[25] N. Freire, J. Estima, and A. Cardoso, "A comparative analysis of PMSG drives based on vector control and direct control techniques for wind turbine applications," Electrical Review, vol. 88, no. 1, pp. 184-187, 2012.

[26] L. Zhang, L. Harnefors, and H.-P. Nee, "Power-synchronization control of grid-connected voltage-source converters," IEEE Transactions on Power Systems, vol. 25, no. 2, pp. 809-820, 2010.

[27] S. Li, T. A. Haskew, and L. Xu, "Conventional and novel control designs for direct driven PMSG wind turbines," Electric Power Systems Research, vol. 80, no. 3, pp. 328-338, 2010.

[28] G. P. Adam, Voltage Source Converter: Modulation, Modelling, Control and Applications in Power Systems, CreateSpace Independent Publishing Platform, Charleston, SC, USA, 1st edition, 2014.

[29] G. Beale, Phase Lead Compensator Design Using Bode Plots, George Mason University, Fairfax, Va, USA, 2010.

[30] G. Beale, Lag-Lead Compensator Design Using Bode Plots, George Mason University, Fairfax, Va, USA, 2003.

[31] G. Beale, Phase Lag Compensator Design Using Bode Plots, George Mason University, Fairfax, Va, USA, 2003.

[32] J. D. Irwin, The Industrial Electronics Hand Book, CRC Press \& IEEE Press, USA, 1997, The Industrial Electronics Hand Book., USA, CRC Press IEEE Press,. 
[33] P. V. Sreeraj, "Design and implementation of PID controller with lead compensator for thermal process," International Journal of Computer Applications, vol. 67, no. 1, pp. 26-31, 2013.

[34] M. R. Islam, S. Mekhilef, and R. Saidur, "Progress and recent trends of wind energy technology," Renewable and Sustainable Energy Reviews, vol. 21, pp. 456-468, 2013.

[35] S. Alsabbah, M. Aldhaifallah, and M. Al-Jarrah, "Design of multiregional supervisory fuzzy PID control of $\mathrm{pH}$ reactors," Journal of Control Science and Engineering, vol. 2015, Article ID 396879, 9 pages, 2015.

[36] M. A. Sahib, B. S. Ahmed, and M. Y. Potrus, "Application of combinatorial interaction design for DC servomotor PID controller tuning," Journal of Control Science and Engineering, vol. 2014, Article ID 576868, 7 pages, 2014.

[37] W. Wang, N. Chen, L. Z. Zhu, and D. G. Xu, "Phase angle compensation control strategy for low voltage ride through of doubly-fed induction generator," in Proceedings of the 1st International Conference on Sustainable Power Generation and Supply (SUPERGEN '09), pp. 1-7, Nanjing, China, April 2009.

[38] H. Geng and G. Yang, "Linear and nonlinear schemes applied to pitch control of wind turbines," Scientific World Journal, vol. 2014, Article ID 406382, 9 pages, 2014.

[39] E. Kamala, A. Aitouchea, R. Ghorbanib, and M. Bayart, "Robust nonlinear control of wind energy conversion systems," International Journal of Electrical Power \& Energy Systems, vol. 44, pp. 202-209, 2013.

[40] I. E. Davidson, H. Muashekele, and N. Mukapuli, "Benguela community/UNAM wind power demonstration project experiences in implementation," Journal of Energy and Power Engineering, vol. 8, pp. 1067-1072, 2014.

[41] A. Rolán, Á. Luna, G. Vázquez, D. Aguilar, and G. Azevedo, "Modeling of a variable speed wind turbine with a permanent magnet synchronous generator," in Proceedings of the IEEE International Symposium on Industrial Electronics (ISIE '09), pp. 734-739, Seoul, Korea, July 2009.

[42] P. Kundur, Power System Stability and Control, McGraw-Hill Education, New York, Ny, USA, 1st edition, 1994.

[43] S. K. Bisoyi, R. K. Jarial, and R. A. Gupta, "Modeling and control of variable speed wind turbine equipped with PMSG," International Journal of Emerging Technologies in Computational and Applied Sciences, vol. 6, pp. 56-62, 2013.

[44] N. S. Nise, Control Systems Engineering, John Wiley \& Sons, New York, NY, USA, 3rd edition, 2000.

[45] A. Kumar, Control System, McGraw Hill, New Delhi, India, 2006.

[46] O. Gomis-Bellmunt, A. Junyent-Ferré, A. Sumper, and J. Bergas-Jané, "Control of a wind farm based on synchronous generators with a central HVDC-VSC converter," IEEE Transactions on Power Systems, vol. 26, no. 3, pp. 1632-1640, 2011.

[47] C. B. C. Blake, GBT or MOSFET: Choose Wisely, International Rectifier, 2010.

[48] S. Keshavarz, Design and evaluation of an active rectifier for a 4.1MW off-shore wind turbine [M.S. thesis], Department of Energy and Environment, Chambers University of Technology, Goteborg, Sweden, 2011.

[49] T. W. Shire, VSC-HVDC based network reinforcement [M.S. thesis], Department of High-Voltage Components and Power Systems, Delft University of Technology, 2009. 


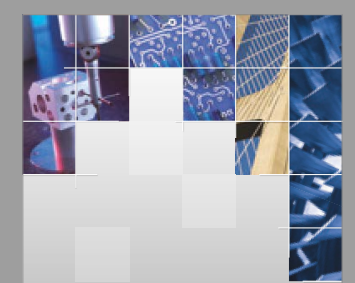

\section{Enfincering}
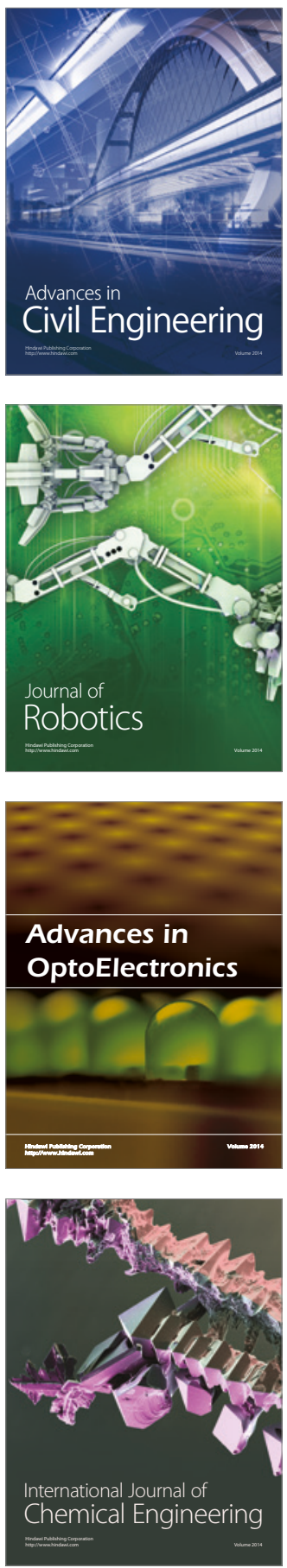

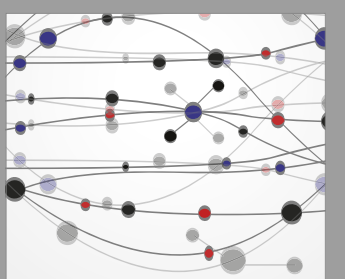

The Scientific World Journal

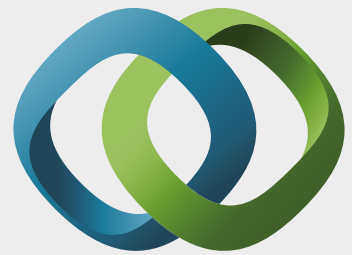

\section{Hindawi}

Submit your manuscripts at

https://www.hindawi.com
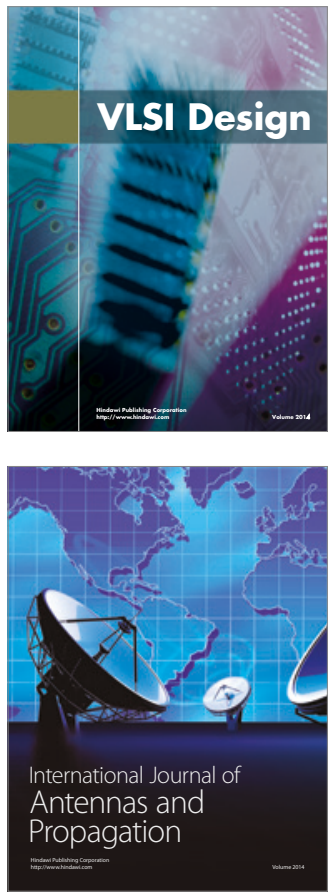

\section{Rotating}

Machinery
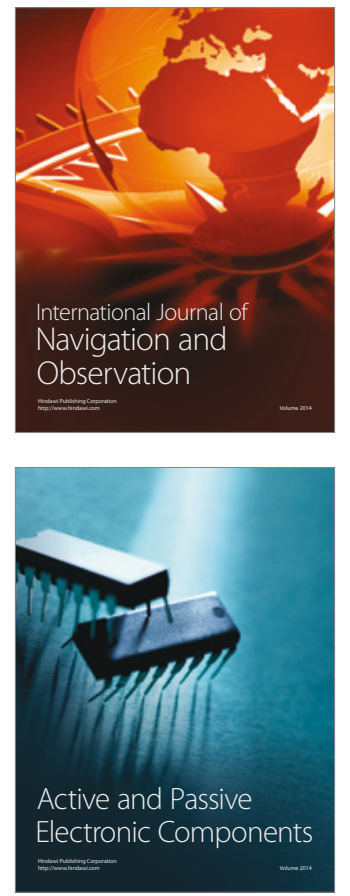
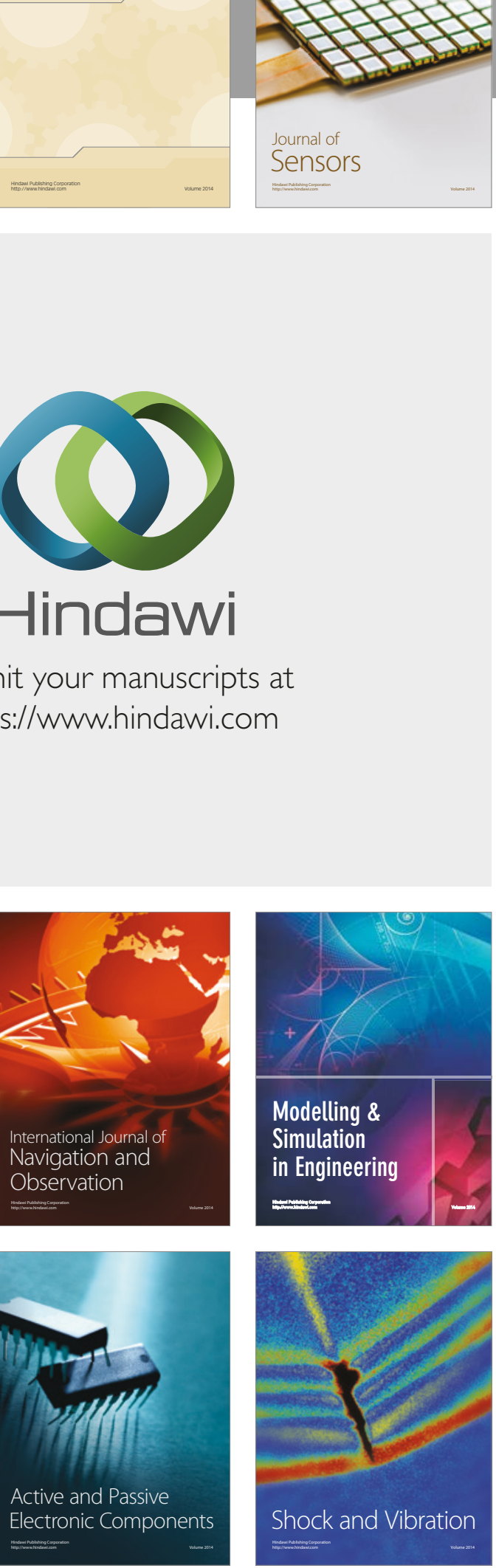
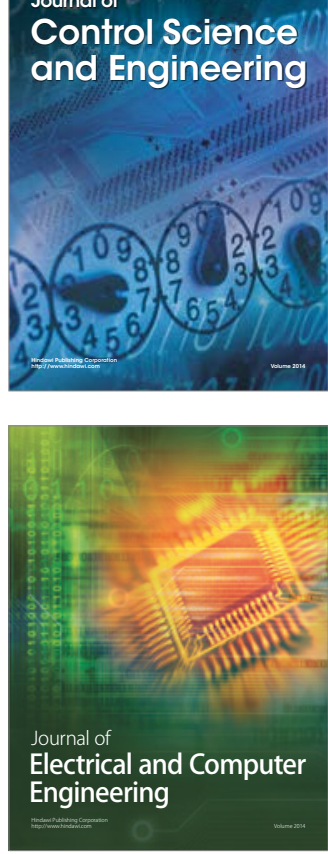

Distributed

Journal of

Control Science

and Engineering
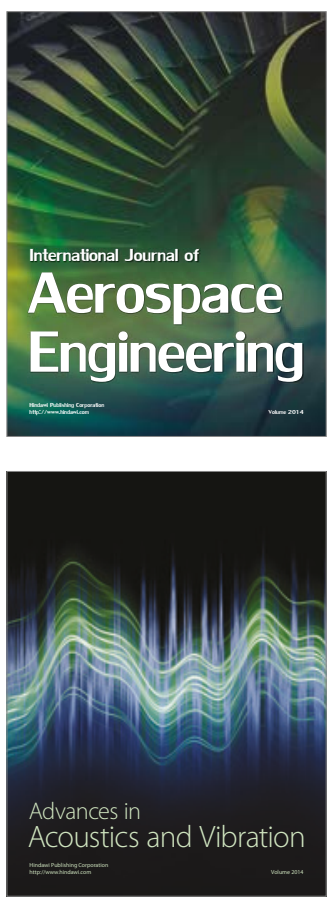

Sensor Networks 